\title{
The role of strategic reports and subjective admission beliefs in explaining the 'ethnic admissions gap' in English secondary schools
}

\author{
Matthew Weldon*
}

December 2018

\begin{abstract}
Data from the English secondary school admissions cycle reveals a substantial ethnic gap in the proportion accessing their chosen schools. Children from minority ethnic groups are, on average, $17 \%$ less likely to be admitted into their top-ranked secondary school, compared to white children. This gap is large even after controlling for socio-economic status and prior attainment. However, constraints on the length of preference lists mean that stated preferences may not be truthful, as parents may have incentives to strategise by excluding preferred schools. By accounting for strategic stated preferences and biased beliefs about chances of admission, this paper recovers parametric estimates of preference parameters and the degree of strategic selection. To examine the relative contribution of geographic sorting, strategies, and market design (mechanism and admission rules), the corrected revealed preference estimates are used to estimate expected welfare under three scenarios. The analysis reveals that both underlying preferences and strategising behaviour exhibit substantial heterogeneity by ethnicity, income and ability. When comparing welfare, I find that differences in admissions priority between white and minority ethnic families create small but significant and consistent differences in welfare. However, larger welfare differences are due to differences in preferences and strategy between the two groups.
\end{abstract}

*Lancaster University, m.weldon@lancaster.ac.uk. This research was undertaken as part of a research project funded by the Nuffield Foundation and led by Professor Ian Walker. I am endebted to Ian for his significant support, advice and guidance. I would especially like to thank Emma Gorman, Ellen Greaves and Andrew Titman for helpful feedback. In addition I would like to thank Allan Little, Steve Gibbons, Emily Hunt, Lindsey MacMillan, Rebecca Allen, Flavio Cunha, Sascha Becker, Thilo Klein, Tom McBride and seminar participants at: ZEW Mannheim; IZA; WOLFE conference; and the staff of the Economics department at Lancaster University for useful discussions and suggestions on the topic. Thanks to the Department for Education for granting me access to the data. 


\section{Introduction}

England has a well-established quasi-market for state-funded secondary schools, in which parents have a right to express their preferences over schools, while parental choice is constrained by capacity at demanded schools, and popular schools are usually oversubscribed. In spite of this, headline figures usually report that the vast majority (around 90\%) of families achieve their first choice of secondary school.

As welfare indicators, these statistics rely on strong assumptions of truthful preference reporting. The admissions system is intended to encourage truthful reporting of parents' preferences. However, constraints on the length of preference lists, together with misunderstandings about the mechanism, introduce the potential for strategic reporting (Haeringer and Klijn, 2009). This not only causes biases in reports of the proportion of parents achieving their first choice, but also makes interpreting choice behaviour using reported preferences difficult. Perhaps most importantly, it adds to the psychological and cognitive burden of parents negotiating a decision that will have long-lasting effects on their children's education.

Moreover, when admissions statistics are disaggregated by location, socio-economic status and ethnicity, substantial heterogeneity is revealed, with minority ethnicities in particular much less likely to achieve their first choice school. These strong empirical patterns in admissions, which have only recently been revealed by the availability of disaggregated data, require an explanation that takes into account geographical sorting, admissions priority rules, heterogeneity of preferences, and the possibility of strategic choice.

This paper takes as its starting point a striking empirical regularity - the 'ethnic admissions gap' in English secondary schools - and asks whether the gap is caused by some features of the way that white and minority ethnic parents choose schools, or can be explained by the strong geographical sorting in populations, or is due to some structural inequality in the design or implementation of the admissions system.

Answering this question requires recovering the true distribution of preferences for school attributes, and the strategic, or admission-regarding, trade-offs that parents make in completing their constrained rank-order lists. This, in turn, requires accurately imputing the admission probability that each child would face if she were to apply to each school. Both of these tasks are challenging.

To address strategic reporting, I estimate a simple model of admission-regarding preferences, which I characterise as an approximation to a structural model of choice under uncertainty, to recover estimates of marginal rates of substitution and welfare for different demographic groups in different locations. This second-stage model requires, as an input, estimates of the admission probability for both listed and unlisted schools.

To impute admission probabilities the paper estimates a structural model of coarse priority and tiebreakers, using the universe of almost 500,000 admission decisions from the 2013 secondary school admissions cycle. Due to the nature of the English admissions system, admission probabilities must be estimated with precise information about the tie-breaker (home-to-school distance) but little information about other aspects of the coarse priority structure. For example, there is no data about whether children have siblings already 
attending schools, or the details of families' religious worship. However, parents have perfect information about these important priority shifters, and this information will plausibly have a large effect on their choice behaviour. This sets up a selection-on-unobservables problem that must be addressed to obtain valid structural predictions of probability of admission.

I exploit the fact that parents observe their child's priority, which means that each family's rank order list potentially contains ample information to impute their priority status. This information is excludable from the structural admissions equation because each school does not observe the entire rank-order list, so if any characteristics of the entire rank-order list are correlated with probability of admission, this must be due to priority-revelation rather than a structural effect. Therefore, we can use parents' choice behaviour to make inferences about their likely priority level. The addition of priority-revealing variables attenuates the omitted variable problem, to allow consistent estimation of the admission probability.

Finally, the paper presents estimates of the gap in expected log welfare, between parents' true preferred school, and the best school that they can achieve given capacity constraints, and the school that they actually achieve. These comparisons provide evidence on the relative contributions of geographic sorting, admissions constraints, and sub-optimal strategies to differences in parental satisfaction between groups.

The analysis supports the findings in previous literature (Gallego and Hernando, 2009; Bertoni et al., 2017; Deming et al., 2014; Burgess et al., 2015) that preferences, measured by marginal rates of substitution between school proximity and school qualities, are heterogeneous across demographic groups. In contrast to previous work, the results emphasise heterogeneity by ethnicity rather than socio-economic status, although both exist. Minority ethnic families have a higher willingness to travel for observable aspects of school quality relating to academic performance, but they appear to place less emphasis on peer-related measures such as the proportion of low income children at a school.

The analysis also reveals that all demographic groups take account of admission probability when selecting which schools to list, but that white, non-poor parents appear to be far more admission-regarding in making choices than all other demographics. The estimates of admission-regarding preferences imply either that white, non-poor parents have lower subjective assessments of admission probability than other parents, or that they are more cautious in selecting schools to list. It is therefore not clear whether estimates reflect differences in risk appetite, or asymmetric information.

The results of the welfare analysis suggest that, before taking capacity constraints into account, there is little to no difference in the quality of choice sets for different demographic groups, implying that geographic sorting plays only a small role in welfare differences. However, taking into account admissions priority rules and the design of the admissions system, a gap emerges in welfare between white and minority ethnic families, and between low income and higher income families. Minority ethnic families have a slightly larger gap between their maximum unconstrained welfare, and the optimal welfare that they can achieve under admissions constraints. This gap increases when comparing the welfare of optimal strategies to the welfare 
actually achieved.

These results imply that the ethnic admissions gap does reflect an underlying welfare gap. This gap is partly due to structural inequalities in the admissions system, which previous research suggests may include faith schools' admission rules (Weldon, 2018). However, the largest part of the welfare gap cannot be explained by structural differences and therefore must be due to behavioural differences. This demonstrates, therefore, that white, non-poor parents' more admissions-regarding choice strategies 'pay off' by allowing them to achieve allocations that are closer to the optimum, and that the English admissions system is far from strategyproof.

There are a number of recent papers that have documented notable differences between white and minority ethnic parents and children's attitudes to education and educational investments in the English context, and the interaction between ethnicity and socio-economic status (Dustmann et al., 2010; Wilson et al., 2011; Chanfreau et al., 2015; Stokes et al., 2015). The evidence suggests that minority ethnic parents tend to have higher educational aspirations, and be more willing to invest in education, than white parents with similar incomes. This paper adds to this evidence base, and is the first to quantify the difference in terms of willingness to trade off convenience (proximity) for academic performance in schools. The paper is also the first to document and analyse an ethnic gap in the chances of accessing one's preferred schools. Understanding this ethnic gap will contribute to understanding the cultural, structural and material determinants of educational investments.

This work is also related to a growing literature combining structural empirical modelling of strategic school choice with topics from market design (Calsamiglia et al., 2010; Klijn et al., 2013; Abdulkadiroğlu et al., 2017; Cantillon, 2017; Chen and Pereyra, 2017; Calsamiglia and Güell, 2018). Within this recent body of work, a handful of papers investigate non-strategyproof markets by explicitly estimating joint models of strategic choice and the probability of admission (Ajayi, 2013; Calsamiglia et al., 2014; Fack et al., 2015; Ajayi and Sidibé, 2016; Agarwal and Somaini, 2018; Luflade, 2018).

Of these papers, Fack et al. (2015) avoids modelling strategic choice, but instead posits methods for recovering the distribution of preferences that are robust to strategy. Calsamiglia et al. (2014) and Agarwal and Somaini (2018) model decision-makers divided into strategic and sincere types, and estimate the proportion of each type in the population. Both papers find that the population contains both strategic and sincere decisionmakers, but do not characterise this variation in terms of demographics.

This paper takes an approach more similar to Ajayi (2013), Ajayi and Sidibé (2016) and Luflade (2018) by estimating parametric subjective beliefs as deviations from an objective probability. Strategic choice is therefore modelled as a matter of degree rather than of discrete types. In relation to this body of work, this paper is the first to explicitly estimate variation in strategic choice to demographic groups.

The paper is structured as follows. The next section introduces the main empirical facts that the paper 

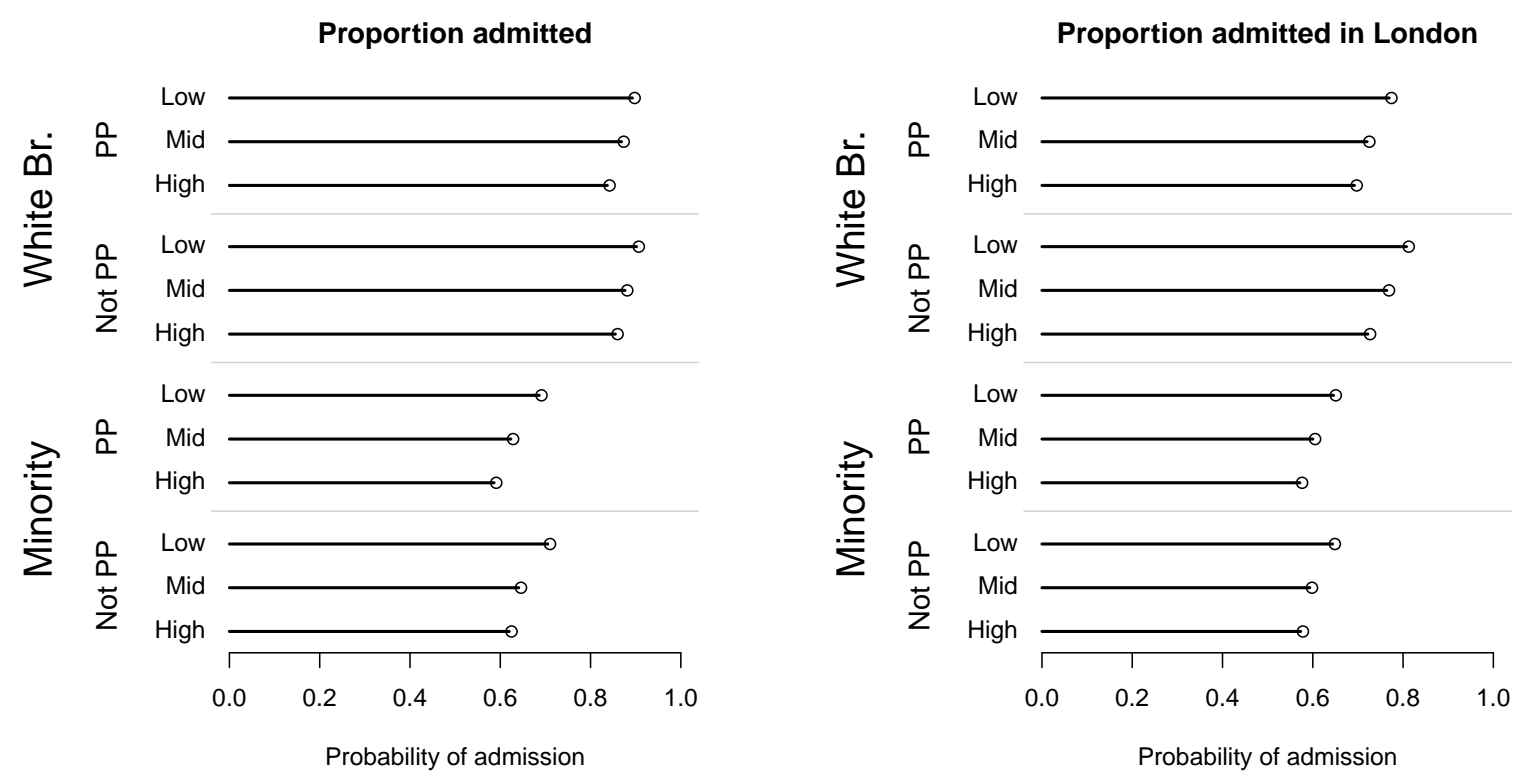

Figure 1: Proportions obtaining first choice by demographic

Proportion of pupils in 2014 cohort by ethnic group, Pupil-Premium status and KS2-attainment tercile (High/mid/low) for England and London. The major patterns are: higher ability children are less likely to obtain a place at their ranked schools; and minority ethnic children are less likely to obtain a place. There is no large difference by PP status.

aims to explain: the demographic, especially ethnic, variation in admissions, and other descriptive facts about the English admissions system. Section 3 describes the English admissions setting, and the data that are used for estimation. Section 4 presents the model for estimating schools' priority rules and the probability of admission. Section 5 introduces the model of strategic school choice under uncertainty, and Section 6 describes how expected welfare counterfactuals are estimated. Section 7 presents and interprets the estimates from the model of strategic choice, while Section 8 analyses the welfare estimates. Finally, Section 9 discusses the implications of the results for policy and concludes.

\section{Empirical evidence on ethnicity and admissions}

The detailed break-down of parental satisfaction statistics by location, ethnicity, ability and other factors only became possible when the Department for Education released individualised preference records (Burgess et al., 2017). Figure 1 shows the proportions of each demographic group obtaining a place at their top-ranked school. It reveals that the difference in the proportion of children from minority ethnic groups achieving their first choice is striking, and remains so after controlling for variation on other demographics.

The variation in probability of admission by KS2 attainment is also large. In this respect note that KS2 attainment is only observed after the admissions process, so any relationship between KS2 and admission must be indirect, via correlations between KS2 and child and family characteristics. Children with higher 

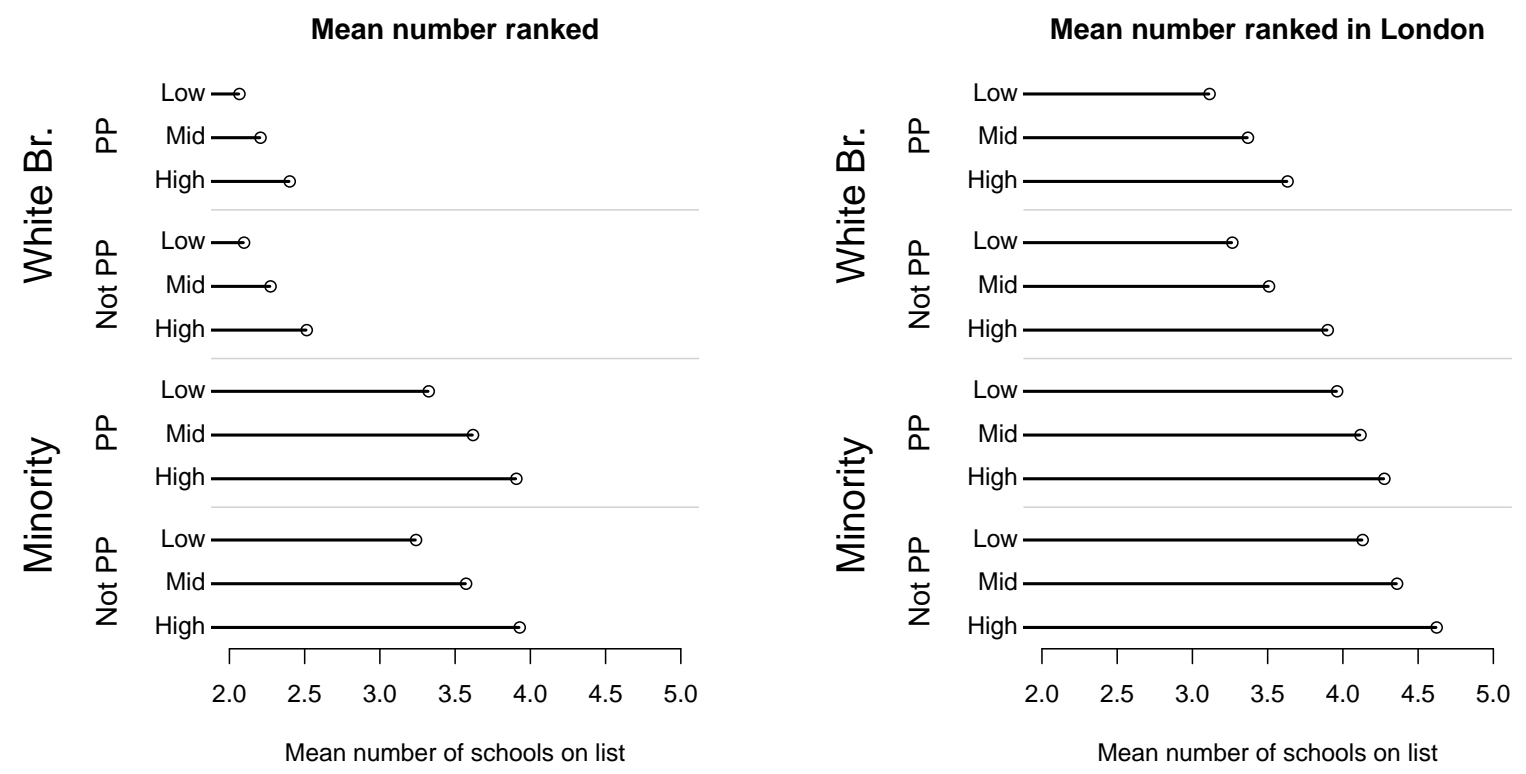

Figure 2: Mean number of schools ranked by demographic

The mean number of schools ranked by applicants in 2014, by ethnic group, Pupil-Premium status and KS2-attainment tercile for England and London. Higher ability children's parents, and minority ethnic children's parents, rank more schools on average. Parents of children eligible for Pupil Premium rank slightly fewer.

KS2 attainment are less likely to obtain a place at their first-choice chool. Conversely, the difference in the percentage achieving first choice of those families eligible for Pupil Premium is more modest.

The minority ethnic population in England is highly clustered, with a large proportion of minority ethnic families living in the largest cities. In general the probability of admission to any school is smaller in urban areas, because the population density is higher and therefore school catchment radii are smaller. To check for possible sensitivity of the patterns to population density, the same figure has been produced only for children living in one of the 32 boroughs of greater London. As expected, in the second panel of Figure 1, which shows admission statistics for London only, the admission gap between white and minority is smaller, but is still large compared to variation by income and attainment.

Of these patterns, the gap in KS2 admissions is more readily explained as a result of parental behaviour. For example, a plausible explanation is that parents of more able children are more willing to state risky options such as popular grammar schools ${ }^{1}$, perhaps mitigated by an 'insurance choice' stated lower down the rank-order list, or the outside option of private schooling for those on higher incomes (Calsamiglia and Güell, 2018). To put it another way, it is quite difficult to imagine a structural difference in access to schools, that would differentially affect more able students. In contrast, the ethnic gap could reflect a behavioural

\footnotetext{
${ }^{1}$ Grammar schools are schools with academic exam entry (see below). The grammar school admission process differs across English local authorities (LAs). Usually children sit the exam and are informed of their result as well as the threshold before their parents complete the rank-order list. However, in some LAs where there are several grammar schools, or where the child is outside the school's catchment area, passing the exam does not guarantee a place at a particular school.
} 
difference, but could also plausibly reflect a structural ${ }^{2}$ gap in the chances of admission. A number of aspects of the admissions system could explain the gap, including: residential sorting causing uneven proximity to good schools; the design of catchment areas; grammar school exam thresholds; religion-based faith school admission rules; or some other aspect of the design of admission markets and oversubscription rules.

Other descriptive evidence supports the hypothesis of differences in decision-making between ethnic groups. Figure 2 shows that in England and also in London, minority ethnic families rank more schools on average than white parents, after controlling for KS2 attainment and Pupil Premium status. Figure 11 in the appendix reveals that minority ethnic parents list schools with slightly higher test scores than white parents, and list schools that are further away on average. Understanding the reasons for these differences, and the extent to which they evidence unequal chances of admission to schools due to geography or other factors, or diversity in school-choice strategies, is the focus of this study.

\section{$3 \quad$ Setting and Data}

\subsection{English secondary school admissions}

In England, children transition from primary school to secondary school at age 11. To apply for a place at a state secondary school in England, parents submit a ranking of their preferred schools. They can list between 3 and 6 schools depending on the Local Authority (LA). Parents must apply within their own LA, but may include any school within or outside their own LA on their list. Local authorities allocate places according to a matching mechanism co-ordinated by each LA or collaborations between neighbouring LAs. Since first-preferences-first mechanisms were banned in 2007 (Department for Education and Skills, 2007), use of the deferred-acceptance (DA) algorithm (Gale and Shapley, 1962) has become ubiquitous (Coldron et al., 2008; Pathak and Sönmez, 2013). For oversubscribed schools, allocation of places is prioritised based on a set of criteria which depends on the school, typically including: whether the child is in the care of the local authority ("looked-after" children); whether the child has an older sibling at the school; and, finally, the distance from the school. In some schools, religious worship or baptism forms the main criterion. In a small proportion of state schools, priority is given to those displaying an aptitude at a particular subject or a range of subjects. Finally, there are a small number of grammar schools which fill all of their places based on performance in an exam, known as the $11+$ exam. If a pupil cannot be allocated to any of their listed preferred schools, they are assigned to a school with spare capacity. In spite of this, many parents list fewer than the maximum allowed number of schools.

Schools can be categorised into six broad groups, according to their admissions policy and ethos.

\footnotetext{
${ }^{2}$ Throughout this paper, the term 'structural' is used to distinguish those aspects of the design of admission rules or the admission system that materially affect the admission probability, as opposed to behavioural differences that only affect the admission probability through self-selection.
} 
Community schools The first group comprises those schools owned and controlled by LAs, comprising $20 \%$ of secondary school places in 2014. These schools generally have simple admissions criteria, prioritising siblings, "looked after" children and those living within a designated zone, with straight-line distance used as a tie-breaker. Until recently the largest group, since 2010 many formerly community schools have been converted into state-funded private schools called "academies".

Non-faith academies ${ }^{3}$ This second group is now the largest group, enrolling $57 \%$ of state-funded secondary school children. These schools have some autonomy to set their own admissions criteria although within the strict guidelines set by the government. Many academies have similar admissions criteria to community schools.

Roman Catholic schools $11 \%$ of secondary school children are enrolled in Roman Catholic schools, making this the largest faith school denomination in secondary schooling. RC schools usually select up to $100 \%$ of their intake on religious grounds. At many schools proof of baptism is sufficient, although at the more popular schools proof of regular church attendance may be required. Some schools reserve a proportion of places for children of other faiths/no faith.

Church of England schools The second largest providers of denominational secondary schooling are Church of England ( $\mathrm{C}$ of $\mathrm{E}$ ) schools (7\% of places). A majority of $\mathrm{C}$ of E schools also require proof of religious worship for some or all places. The admissions criteria of CofE schools are more heterogeneous, and support for religious selection less unanimous in the Anglican sector than in the Roman Catholic sector.

Other faith schools There are a very small number (less than 1\%) of schools with religious denomination other than Christian. These schools often operate faith-based admissions criteria for some or all places.

Grammar schools There are 162 academically-selective grammar schools (enrolling 5\% of children) - the remainder of a much larger system of academic selection that existed prior to the 1970's. To obtain a place at a grammar school children are required to sit an academic exam. In some Local Authorities all 11-year old children sit a common exam, whereas in others only children who wish to apply to a school sit the school's exam.

Strict government guidelines regulate the admissions criteria that schools are permitted to use. Some unlawful criteria include: interviews or other face-to-face contact; rank-order (eg. first-preferences-first); parental contributions or volunteering. In addition, new schools have more stringent restrictions on religious and academic selection than existing schools. All schools, except community schools, may opt to receive a list of applications (without information on the preference order) and rank them before sending the ranking back to the LA for the matching to be computed. For community schools the LA computes the ranking.

It is worth noting that, in contrast to many other countries operating centralised school admissions, lotteries are almost unheard of as a priority tie-breaking mechanism. The final tie-breaker for the majority of

\footnotetext{
${ }^{3}$ Many faith schools and grammar schools are also designated as academies, but for the purposes of this study this category only includes those academies which are not faith schools or grammar schools.
} 
community, academy and religious schools is straight-line distance between the school and the pupil's home address. The distance tiebreaker creates the conditions for house prices to be affected by the proximity of good schools (Gibbons and Machin, 2006; Gibbons et al., 2013). This reliance on geographical priorities means that admission to schools is deterministic and depends only on priority, distance from the school, and the actions of other parents. However, uncertainty about the actions of other parents, combined with possible uncertainty about one's own priority, introduces subjective uncertainty from the point of view of the decision-maker.

\section{$3.2 \quad$ Strategic reporting}

There are two aspects of this system that may lead to strategic reporting. First, although, under studentproposing DA, truth-telling is a weakly dominant strategy (Abdulkadiroğlu and Sönmez, 2003) this is not necessarily the case when preference lists are short and parents are forced to truncate their preference reports. Haeringer and Klijn (2009) show that, if the maximum rank-order list size $S$ is smaller than the number of acceptable schools, it is no longer a dominant strategy to list one's top $S$ schools truthfully. Specifically, it may be optimal to remove some of the top $S$ schools from the list, so as to leave space to allow less-preferred schools to be included. However, it is always a dominant strategy to list those schools which are included in the list in the order of true preference. I present evidence that in many Local Authorities, 3 to 6 slots are not sufficient and therefore parents are incentivised to consider their chances of admission when reporting a subset of their true preferences, to avoid being assigned to a school with spare capacity.

The second aspect is the complexity of the matching mechanism, and uncertainty in admissions probabilities, that leads to erroneous beliefs about optimal strategies. It is suspected that misunderstanding of the rules of the matching mechanism is widespread.

In the presence of strategic reporting, the observed proportion of parents achieving their reported firstchoice school is not a good indicator of welfare. In addition, differences in this measure by ethnicity, socio-economic status or other demographic variables may reflect differences in strategic behaviour, rather than real differences in welfare.

\subsection{Data and sampling}

In 2014 the English Department for Education began to collect individual reported preference lists from all Local Authorities in England. The rank-order lists constitute parents' formal applications to secondary schools through local authority clearing houses. I exploit the first two cohorts of secondary school entrants in the 2014 and 2015 admissions cycles. Each cohort contains rank-order lists for around 500,000 children who are in their final year of primary school (aged 10-11), linked to their home postcode, ethnicity, gender, Pupil Premium status (a proxy for low income), and primary school test scores from the National Pupil Database 
(NPD). From the home postcode I can calculate their location and school proximity ${ }^{4}$. The NPD also provides detailed information on schools, including location, test scores, demographic composition, governance and religious denomination. I also obtain current and historical government inspections (Ofsted) scores from the online schools database, Edubase.

Individuals are eligible for inclusion in the sample if there exists a rank-order list record for the child, and additionally they are either included in the year 6 census $^{5}$ (final year of primary school), or the year 7 census (first year of secondary school), or both, and their home postcode, ethnicity and KS2 attainment ${ }^{6}$ are not missing. This means that those children transitioning from a private primary school, or who eventually transition to a private secondary school, are potentially included in the sample as long as their parents participate in the state-school admissions cycle.

The main focus of the paper is on ethnic variation in admissions. However, ethnic group is correlated with material and educational contextual factors. It is important to control for these factors to obtain a clear picture of variation in admissions decision-making and outcomes due to ethnicity. To this purpose, the paper employs a consistent demographic cross-classification to allow for variation in incomes, academic attainment, and ethnicity.

Much of the existing work on school choice focusses upon variation by socio-economic status or incomes, and finds significant variation, so it is important to allow for this dimension in our classification by including Pupil Premium status as a demographic indicator. The Pupil Premium (PP) is an initiative that awards additional funds to schools for each child on roll who is eligible. Pupils are eligible for PP if they have been eligible for Free School Meals at any time in the last six years, and pupils are eligible for Free School Meals if their parents have low incomes and are in receipt of certain benefits. PP is therefore a proxy for low incomes. I also control for variation in attainment at Primary school by including tercile of Key Stage 2 (KS2) SAT scores in the classification. KS2 tests are taken by children at the end of the final year of primary school (at the age of 11) and give an aggregated score for ability in English and Mathematics. It is important to note that, as the admissions cycle takes place at the beginning of the final year of primary school, children will not have taken the test when their parents are choosing schools, and schools will not observe KS2 attainment. However, KS2 terciles are used as a correlate of unobservable family and child characteristics that affect school choice and admissions. It is possible that KS2 terciles are endogenous with respect to admissions outcomes. However, this is unlikely as KS2 tests are low-stakes tests from the point of view of the child and parents. Since they have no bearing on admissions, there are no incentives for parents or children to alter effort in response to admission decisions.

However, KS2 may be correlated with parental unobservables. In particular, KS2 outcomes may be af-

\footnotetext{
${ }^{4}$ School proximity is measured as the straight-line distance between the centroid of the home postcode and the centroid of the school postcode, in kilometres.

${ }^{5}$ Children in private schools are not included in the National Pupil Database census.

${ }^{6}$ A small number of pupils with missing Pupil Premium status were imputed as not PP.
} 
fected by spillovers from parental investments in gaining entry to grammar schools, such as helping children with homework, maintaining discipline and procuring private tutoring. KS2 tercile therefore incorporates information about the parents', as well as the children's, unobservable type with respect to human capital investments. To the extent that these investments are predetermined at the time of school choice this does not bias estimates, but it should be borne in mind when interpreting results.

Ethnicity is measured in the NPD based on parental reports. There are 18 ethnic groups in the original data, listed in Table 5. For most of the analyses in the paper a two-way white/minority classification has been used. While this two-way classification hides all distinctions between non-white ethnic groups, it ensures that the aggregated sample size of the minority group is large enough when cross-classified by income and attainment, and also ensures sufficiently large sample sizes outside London and the major cities. The fourway classification has been used in some of the graphical descriptive statistics. Weldon (2018) presents descriptive analyses and also a discrete choice model estimated using the four-way classification, with the conclusion that the important distinction with regards to school choice and admissions is between white families and all other ethnic groups. Ethnicity is related to other constructs such as nationality, religion, language and the length of time spent living in the UK. It is possible that phenomena ascribed to ethnicity in the paper should more properly be ascribed to one of these other constructs. However, the other constructs are not recorded in the data used in this study.

There are therefore 12 demographic groups defined by the cross-classification of ethnicity (white/minority), Pupil-Premium status (eligible/not eligible) and KS2 attainment terciles (high/middle/low). For each child we observe their demographic group, home location at the postcode level, rank-order list, the offered school and the school that the child was subsequently enrolled in.

\section{Estimating admission probabilities}

To model strategic choice under uncertainty about admission probabilities, the usual approach is to undertake a two-stage analysis, where the first stage involves modelling the admission probabilities themselves, or beliefs about them. Several authors have addressed this empirical problem. The most common approach to constructing admission probabilities is to take account of uncertainty in the admission thresholds, or cutoffs, at each school caused by the unknown distribution of other applicants and their preferences or strategies. In some applications authors also take account of uncertainty about the priority rule, the realised priorities, or both.

In order to estimate a portfolio-choice model for exam-based admission to Ghanian secondary schools, Ajayi and Sidibé (2016) model subjective probabilities of admission derived from uncertainty about both personal exam performance, and score thresholds (cutoffs) of schools. Decision makers infer exam cutoffs with error by observing cutoffs in previous years at the same school. Luflade (2018) also models the distribution of 
exam admissions cutoffs as inferred from previous years' observations, for a model of university choice under constrained lists in Tunisia.

Fack et al. (2015) obtain data on students' priority scores and schools' cutoffs, and use this information to model preferences under more or less stringent assumptions of strategic choice. This involves modelling admission as a deterministic decision. However, they do not explicitly consider admissions uncertainty.

Agarwal and Somaini (2018) assume perfect knowledge of coarse student priorities, with uncertainty introduced by the actions of other decision-makers and the random tiebreaker. Rather than estimating atomic success probabilities for each school, Agarwal and Somaini (2018) estimate the full vector of assignment probabilities for a given ranked list, and therefore accommodate the rank-dependent priorities of the immediate-acceptance algorithm in use in Cambridge, Massachusetts. Admission probabilities are estimated by resampling and simulation of matchings. The relatively small cardinality of the set of ranked lists in their application means that this approach is computationally feasible. Calsamiglia et al. (2014) also estimates admission probabilities consisting of a deterministic priority plus a random tiebreaker.

In the current study, admission probabilities must be estimated with precise information about the tiebreaker (distance from the school) but little information about other aspects of the coarse priority structure. For example, there is no data about whether children have siblings already attending schools, or the details of families' religious worship. However, parents have perfect information about these important priority shifters, and this information will plausibly have a large effect on their choice behaviour. This sets up a selectionon-unobservables problem that must be addressed to obtain valid structural predictions of probability of admission. However, the fact that parents observe their own priority means that each family's rank order list potentially contains ample information to impute their priority status. This information is excludable from the structural model of admissions priority because each school does not observe the entire rank-order list, so if any characteristics of the entire rank-order list are correlated with probability of admission, this must be due to priority-revelation rather than a structural effect. Therefore, we can use parents' choice behaviour to make inferences about their likely priority level.

For example, if children whose parents submit a shorter rank-order list are more likely to be admitted to their first-choice school, this must be due to a correlation between being confident of admission into the top-ranked school, and not feeling the need to list the maximum number of schools. It cannot be directly an admissions priority rule, since each school does not know the length of each child's rank-order list. Therefore this information cannot directly be used to impute counterfactual admission for a child who did not apply to a school, but it can be used to 'mop up' omitted variable bias due to selection-on-unobservables.

This "self-revelation" approach is related to Heckman (1979) corrections. The control-function approach was derived for multinomial choice models by Dubin and McFadden (1984), and employed by Abdulkadiroğlu et al. (2017) to estimate causal effects of schooling. It is also related to the matching models of Dale and Krueger (2002). However, the approach taken in this paper differs in that it relies on observables correlated 
with unobserved priority, rather than attempting to model the distribution of the unobservables directly. This has the advantage of placing weaker assumptions on the functional form of unobservables.

Priority-revealing variables, excluded from the structural admissions equation, attenuate the omitted-variables bias and are then integrated out of the average structural function (ASF) (Blundell and Powell, 2004). The latter is used for prediction of admissions probability on the second-stage dataset.

\subsection{Identification of the Average Structural Function}

Azevedo and Leshno (2016) develop a model of large many-to-one stable matching markets, such as school markets, and show that the equilibrium matching can be characterised by a set of market-clearing priority cutoffs at each school, which play a role analogous to market-clearing prices. Agarwal and Somaini (2018) build upon this to develop a general model of admission mechanisms which, in large markets, can be characterised by priority scores which may depend upon the decision-makers' reports, and market clearing cutoffs. They show that this model applies to a large class of stable and non-stable matching mechanisms.

Most admissions oversubscription policies in England share a common lexicographic structure. Two or more coarse priority groups define the high-level ranking, and a continuous measure breaks ties between children in the same priority group. The coarse priority structure can be represented by an index function $\phi:\{0,1\}^{K} \rightarrow \mathbb{Z}_{\geq 0}$, that assigns to each child $i$ with binary criterion-vector $\mathbf{c}_{i}$ of length $K$ a priority group $\phi\left(\mathbf{c}_{i}\right) \in\left\{0,1, \ldots, N_{\phi}\right\}$. The school fills its quota in order of priority from bottom to top, so that children with priority zero are allocated first. A continuous tie-breaker measure is used to assign priorities within each priority group. In the US and other countries it is common for a random lottery to be used to break ties. However, in England lotteries are rare and distance is the most commonly-used tie-breaker. West et al. (2004) reported that $86 \%$ of secondary schools used distance as a tie-breaker. Since then the proportion is likely to have risen, since successive legislation has narrowed the range of legal priority rules. The tie-breaker can be incorporated into the ranking function by defining a monotonic mapping $\nu:[0, \infty) \rightarrow[0,1)$. Then the strict ranking of applicants $i$ by school $j$ is determined by $\eta_{j}\left(\mathbf{c}_{i j}, d_{i j}\right)=\phi_{j}\left(\mathbf{c}_{i j}\right)+\nu\left(d_{i j}\right)$.

However, we do not observe realisations of the coarse ranking function. Instead, we observe individual admission decisions $y_{i j}\left(\mathbf{c}_{i j}, d_{i j}\right) \in\{0,1\}$. Because of this, it is not possible to recover the entire coarse ranking function. However, observing $y_{i j}$ allows for local identification of the index function and index function thresholds around the marginal priority group (i.e. the priority group for whom the distance tiebreaker is decisive). Figure 3 shows that observing repeated admission decisions at either side of the sharp discontinuity at the cutoff enables identification of the proportion of the population with criterion-vector $\mathbf{c}_{i j}=c$ belonging to the marginal coarse priority group, defined as the group for which the distance tiebreaker is decisive. This in turn identifies the parameters $\varphi^{*}$ of the local index function and the lower and upper thresholds $\left(\phi_{1}, \phi_{2}\right)$ of the local index function to scale and location for the marginal priority group. 


\section{Identification of 'local' coarse priorites}

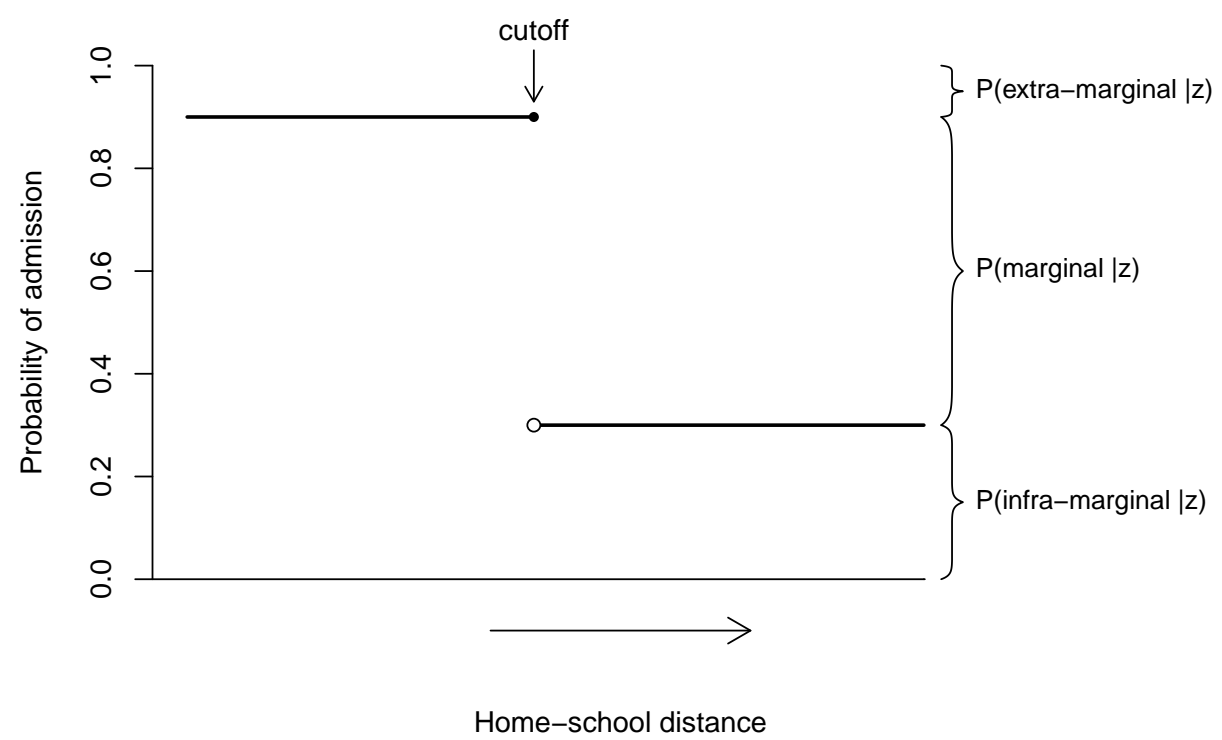

Figure 3: Coarse priority plus cutoffs model

Diagram of the structural mixture model that jointly estimates membership of the marginal coarse priority group, and the distance tie-breaker cutoff, for each school. If year-on-year variations in demand are not too large, the position of the distance cutoff will vary, but the proportions belonging to the three identified priority groups will remain constant and admission decisions will only depend on these three groups.

By extension the proportions belonging to the infra-marginal group $\mathcal{I}$, grouping all coarse priorities higher than the marginal group, and the extra-marginal group $\mathcal{E}$ grouping priorities lower than the marginal group, are also identified.

In the current application the criterion-vectors $\mathbf{c}_{i}$ are not observed. Instead, we observe a vector of proxies for priority $\mathbf{z}_{i j}$. This vector can be further split into pre-determined priority-shifters $\mathbf{z}_{1 i j}$, and endogenous priority-revealing variables $\mathbf{z}_{2 i j}$. An example of the first kind of variable is ethnicity, which may be correlated with religious worship and the likelihood of having older siblings at a school, and is pre-determined at the time of decision-making. An example of the second kind might be the size or composition of the full ranked list, besides the current school. For the current application, variables that are endogenous with respect to long-run strategies but pre-determined at the time of application, such as residential location, primary school choice and prior attainment, are treated as priority shifters and included in $\mathbf{z}_{1 i j}$. The average structural function conditions on priority shifters, and sums over the population distribution of priority-revealing variables.

Although the full priority function is not identified, the local priority index function (i.e. the index function that predicts membership of the marginal priority group and its neighbours) is sufficient for predicting admission probabilities and counterfactual matchings as long as the year-on-year variation in the cutoff is not too large, that is, as long as the cutoff varies so that the marginal priority group remains the marginal 
priority group. This assumption can be checked by simulating allocations using resampled rank-order lists and the estimated rankings.

\subsection{Empirical specification}

The data is a set of one or more admission decisions $\mathbf{y}_{i}=\left\{y_{i r_{s}}\right\}_{s}$ for each individual ${ }^{7}$, the observable proxies for priority criteria $\mathbf{z}_{i}$ and the home-to-school distances $\mathbf{d}_{i}$. The likelihood is

$$
P\left(y_{i j} \mid \boldsymbol{\varphi}, \Delta_{j}, z_{i j}, d_{i j}\right)= \begin{cases}P\left(i \in \mathcal{I}_{j} \mid \mathbf{z}_{i j}\right)+P\left(i \in \mathcal{M}_{j} \mid \mathbf{z}_{i j}\right) \mathbf{1}\left\{d_{i j}<\Delta_{j}\right\} & \text { if } y_{i j}=1 \\ P\left(i \in \mathcal{E}_{j} \mid \mathbf{z}_{i j}\right)+P\left(i \in \mathcal{M}_{j} \mid \mathbf{z}_{i j}\right) \mathbf{1}\left\{d_{i j} \geq \Delta_{j}\right\} & \text { if } y_{i j}=0,\end{cases}
$$

where $\left(\mathcal{I}_{j}, \mathcal{M}_{j}, \mathcal{E}_{j}\right)$ are the infra-marginal, marginal and extra-marginal priority groups for school $j$. The group-membership probabilities are estimated using an ordered logit threshold-crossing model with separate parameters $\varphi_{t_{j}}$ for each school type $t$, where

$$
\begin{aligned}
P\left(i \in \mathcal{E}_{j} \mid \mathbf{z}_{i j}\right) & =1-\operatorname{logit}^{-1}\left(\boldsymbol{z}_{i j}^{\prime} \boldsymbol{\varphi}_{t_{j}}-\phi_{1 t_{j}}\right), \\
P\left(i \in \mathcal{M}_{j} \mid \mathbf{z}_{i j}\right) & =\operatorname{logit}^{-1}\left(\boldsymbol{z}_{i j}^{\prime} \boldsymbol{\varphi}_{t_{j}}-\phi_{1 t_{j}}\right)-\operatorname{logit}{ }^{-1}\left(\boldsymbol{z}_{i j}^{\prime} \boldsymbol{\varphi}_{t_{j}}-\phi_{2 t_{j}}\right), \\
\text { and } \quad P\left(i \in \mathcal{I}_{j} \mid \mathbf{z}_{i j}\right) & =\operatorname{logit}^{-1}\left(\boldsymbol{z}_{i j}^{\prime} \boldsymbol{\varphi}_{t_{j}}-\phi_{2 t_{j}}\right) .
\end{aligned}
$$

The full vector of parameters is $\left(\left\{\phi_{1 t}, \phi_{2 t}, \varphi_{t}\right\}_{t \in T},\left\{\Delta_{j}\right\}_{j \in J}\right)$ where $\left(\phi_{1 t}, \phi_{2 t}\right)$ are lower and upper thresholds for the marginal priority group for school type $t, \varphi_{t}$ are priority-model parameters, and $\Delta_{j}$ is the distance cutoff for school $j$.

Variables in $\mathbf{z}_{1}$ include each student's primary school denomination (RC, C of E, other), two-way ethnicity (white, minority), Pupil-premium status, binned KS2 test score, and an indicator for whether the school is the student's nearest school, intended to proxy geographical priority areas. Variables in $\mathbf{z}_{2}$ include the size of the rank-order list, the position in the ranking of the current school, the number of grammar schools ranked (excluding the current school), and the number of faith schools ranked (excluding the current school).

The average structural function (Blundell and Powell 2004) may be used with the estimated parameters for imputation of $\rho_{i j}$ into the second stage dataset. The average structural function is defined as

$$
A S F\left(\boldsymbol{z}_{1}, d ; \boldsymbol{\varphi}, \Delta\right)=\sum_{i=1}^{N} P\left(i \in \mathcal{I}_{j} \mid \boldsymbol{z}_{1}, \boldsymbol{z}_{2 i j}\right)+P\left(i \in \mathcal{M}_{j} \mid \boldsymbol{z}_{1}, \boldsymbol{z}_{2 i j}\right) \mathbf{1}\{d<\Delta\} .
$$

Integration over the population distribution can more easily be achieved by taking quantile means of $\boldsymbol{z}_{2}$ in the population, and redefining as a sum over quantiles $q$ :

$$
A S F\left(\boldsymbol{z}_{1}, d ; \boldsymbol{\varphi}, \Delta\right)=\sum_{q=1}^{Q} P\left(i \in \mathcal{I}_{j} \mid \boldsymbol{z}_{1}, \overline{\boldsymbol{z}}_{2 q}\right)+P\left(i \in \mathcal{M}_{j} \mid \boldsymbol{z}_{1}, \overline{\boldsymbol{z}}_{2 q}\right) \mathbf{1}\{d<\Delta\} .
$$

\footnotetext{
${ }^{7}$ Each individual lists one or more schools. If the pupil is admitted into her first choice we only observe one admission decision: $y_{i r_{1}}=1$. If the pupil is admitted into the school at slot $w$ we observe $y_{i r_{s}}=0$ for $s \in 1, \ldots, w-1$, and $y_{i r_{w}}=1$.
} 


\section{Estimating preferences under strategic choice}

Modelling the rational selection of schools in a constrained rank-order list is a hard problem. Despite considerable recent attention devoted to the topic, the full model of expected utility maximisation remains intractable for any but the smallest school markets, even after imposing parametric assumptions. For this reason, this paper introduces a simple reduced form model, and characterises it as an approximation to the full model of expected utility maximisation under uncertainty. First, let us introduce the full model.

The canonical model of strategic school choice is the downward recursive portfolio choice model of Chade and Smith (2006). Under this model, the decision-maker chooses a portfolio of items in a sequential lottery to maximise her expected utility subject to either a non-negative cost per item, or a maximum quota of items in the lottery, or both. Lottery weights in each slot are composed from the product of the individual failure probabilities of items in previous slots, and the individual success probability of the item in the current slot. Adapting the notation of Agarwal and Somaini (2018), the lottery $L_{R_{i}, \rho_{i}}$ therefore depends not only on individual success probabilities $\rho_{i}$, but also upon the ranking $R_{i}$.

In a school choice context, items are schools $j$, and we assume that the decision-maker $i$ optimises her stated preference list, subject to a maximum number of slots $S$. Parents have private indirect utilities for all schools $\left\{v_{i j}\right\}_{j \in J}$ and choose the list that maximises expected utility

$$
u_{i}=\rho_{i r_{1}} v_{i r_{1}}+\left(1-\rho_{i r_{1}}\right) \rho_{i r_{2}} v_{i r_{2}}+\cdots+\prod_{r^{\prime}=1}^{S-1}\left(1-\rho_{i r^{\prime}}\right) \rho_{i r_{S}} v_{i r_{S}}+\prod_{r^{\prime}=1}^{S}\left(1-\rho_{i r^{\prime}}\right) u_{i S}^{+} .
$$

$u_{i S}^{+}$is the expected utility of failing to be allocated to any school and being assigned to a school with spare capacity by the local authority.

As the name implies, the downward recursive portfolio problem admits a recursive definition. The expected utility of the last option, conditional upon being rejected from schools ranked higher, is $u_{S-1}^{+}=\rho_{i r_{S}} v_{i r_{S}}+$ $\left(1-\rho_{i r_{S}}\right) u_{i S}^{+}$. At each slot $s$ the expected utility, conditional on being rejected from schools above is

$$
u_{i s-1}^{+}=\rho_{i r_{s}} v_{i r_{s}}+\left(1-\rho_{i r_{s}}\right) u_{i s}^{+} .
$$

The expected utility of the entire list is therefore

$$
u_{i}=u_{i 0}^{+}=\rho_{i r_{1}} v_{i r_{1}}+\left(1-\rho_{i r_{1}}\right) u_{i 1}^{+} .
$$

Note that the existence of a recursive definition of the problem does not imply that there is a recursive solution to the problem. The definition above implies that at each slot $s$ the decision-maker conditions on both the set of schools above that slot and the set of schools below that slot. An exhaustive search of all possible ranked lists quickly becomes infeasible. For example, a London resident deciding which six schools to list, if only considering schools in the same borough (typically about 15 schools) would have to consider 
$15 ! /(15-6) ! \approx 3.6$ million possible lists. The empirical evidence suggests that parents do not limit themselves to only considering schools in the same borough.

In spite of this combinatorial complexity, Chade and Smith (2006) show that the decision-maker can select an optimal lottery sequentially in $O(N \times S)$ time by adding, at each stage, the item (school) that provides the largest marginal improvement in expected utility. However, the solution is not sequential in the sense of progressing, forwards or backwards, through the sequence of slots $s \in 1, \ldots S$. At each stage, an addition can be at the beginning, in the middle, or at the end of the existing list. This result is therefore of little use for constructing a structural empirical model, as the researcher does not know the order in which schools were added, and a model combining all possible paths would be of similar complexity to an exhaustive search ${ }^{8}$.

To complete the notation, denote by $R_{i s}^{-}=\left(r_{i 1}, r_{i 2}, \ldots, r_{i s-1}\right)$ the set of 'upstream' listed schools up to, but not including, the $s^{\prime}$ th listed school, and denote by $R_{i s}^{+}=\left(r_{i s+1}, r_{i s+2}, \ldots, r_{i S}\right)$ the set of 'downstream' schools ranked below school $r_{s}$, and $R_{i 1}^{-} \cup R_{i S}^{+}=\varnothing$. To construct a probability model note that, at slot $s$, conditioning on $R_{i s}^{-}$, a parent chooses a school $r_{s}$ such that

$$
r_{s}=\underset{j \in J \backslash R_{i s}^{-}}{\arg \max } \rho_{i j} v_{i j}+\left(1-\rho_{i j}\right) E\left[u_{i s}^{+} \mid j\right] .
$$

The full likelihood, conditioning on $\boldsymbol{u}^{+}=\left\{E\left[u_{i s}^{+} \mid j\right]\right\}_{s \in 1, \ldots, S ; j \in 1, \ldots, J}$ therefore gives

$$
\mathcal{L}^{*}\left(R_{i} \mid \boldsymbol{u}^{+}\right)=\prod_{s=1}^{S_{i}} P\left(\rho_{i r_{s}} v_{i r_{s}}+\left(1-\rho_{i r_{s}}\right) E\left[u_{i s}^{+} \mid r_{s}\right] \geq \rho_{i j} v_{i j}+\left(1-\rho_{i j}\right) E\left[u_{i s}^{+} \mid j\right], \quad \forall j \in J \backslash R_{i s}^{-}\right) .
$$

Agarwal and Somaini (2018) show that utilities are non-parametrically identified in the downward recursive model. However, the unconditional likelihood is intractable as it involves integration over the complex joint distribution of the random variables $\boldsymbol{u}^{+}$.

However, this formulation suggests a simplifying approximation. Assume that, at any slot $s, E\left[u_{i s}^{+} \mid j\right]<<v_{i j}$ for all $j \in J \backslash R_{i s}^{-}$. Then the contribution of the downstream utility becomes negligible, and the likelihood can be approximated by

$$
\tilde{\mathcal{L}}\left(R_{i}\right)=\prod_{s=1}^{S_{i}} P\left(\rho_{i r_{s}} v_{i r_{s}} \geq \rho_{i j} v_{i j}, \forall j \in J \backslash R_{i s}^{-}\right) .
$$

This approximation relies on a strong assumption of large expected utility losses from failure to be admitted at each slot. This assumption will be more accurate to the extent that the prospect of the administrativelyassigned school is sufficiently bad, and it is sufficiently likely.

Specifying a Cobb-Douglas cardinalisation of indirect utility leads to a log-linear model for the approximate slot utility

$$
\log u_{i j}^{s} \approx \alpha_{D(i) j}+\beta_{D(i)} \log d_{i j}+\delta_{D(i) s} \log \rho_{i j}+\epsilon_{i j}
$$

\footnotetext{
list

${ }^{8}$ The Marginal Improvement Algorithm (MIA) is used in the welfare analysis to calculate the expected utility of the optimal
} 
where

$$
\alpha_{D(i) j}=\sum_{k=1}^{K} \gamma_{D(i) k} x_{j k}+\xi_{j}
$$

preference parameters are indexed by pupil demographic group $D(i)$, and $\delta_{D(i) s}$ is a scaling parameter that represents subjective probability weighting (see below). Only $\delta_{D(i) s}$ varies by slot. The other parameters are structural parameters that characterise the shape of indifference curves between aspects of school quality, and as such do not vary as the choice set changes along the rank-order list.

If $\epsilon_{i j}$ is distributed as a standard Extreme-Value Type I (Gumbel) variable, the approximate likelihood becomes a ranked logit

$$
\tilde{\mathcal{L}}\left(R_{i} \mid \mathbf{x}, \boldsymbol{d}_{i}, \boldsymbol{\rho}_{i},(\beta, \gamma, \delta)_{D(i)}\right)=\prod_{s=1}^{S_{i}} \frac{\exp \left(\alpha_{D(i) r_{s}}+\beta_{D(i)} \log d_{i r_{s}}+\delta_{D(i) s} \log \rho_{i r_{s}}\right)}{\sum_{j \in J R_{i s}^{-}} \exp \left(\alpha_{D(i) j}+\beta_{D(i)} \log d_{i j}+\delta_{D(i) s} \log \rho_{i j}\right)} .
$$

School covariates $\boldsymbol{x}$ include: the proportion of pupils achieving at least five GCSE ${ }^{9}$ grades at A* to C (AC5); the proportion of pupils eligible for Pupil Premium (a low-income proxy) in the school; the proportion of white pupils in the school; the school's most recent Ofsted inspection ${ }^{10}$ grade (dummies for Outstanding and Good); and a separate dummy for each school type (Community, RC, C of E, Other faith, Grammar) excluding Academy as the reference level.

\subsection{Formation of beliefs about admission}

Substituting admission probabilities estimated on the previous cohort's data into the approximate choice model implicitly assumes that parents form beliefs about admission based on the previous year's admissions. That is, parents are backward-looking in assessing the probability of admission. Although strong, this assumption is not implausible and has been made in other literature in the field (Ajayi, 2013; Luflade, 2018, cf.). Agarwal and Somaini (2018) test the assumption against an alternative where parents use the current year's admissions. In the English system demographics and school capacities are rather stable so it is unlikely that admission probabilities would change enough year-on-year to materially affect inferences.

In the literature on behavioural choice under uncertainty it is usual to allow decision-makers probability assessments to differ systematically from objective probabilities (Kahneman and Tversky, 1979; Quiggin, 1982). Under the approximate admission-regarding model it is straightforward to allow non-linear distortions to objective probabilities to enter into the approximate log expected utility. Inclusion of the parameter $\delta$ in the specification is equivalent to a probability weighting function $w(\rho)=\rho^{\delta}$. This is a one-parameter special case of the Prelec weighting function $w(\rho)=\exp \left(-\delta(-\log \rho)^{\alpha}\right)$ (Prelec, 1998).

Given that the model is only approximate, and admission probabilities are imputed, I avoid taking the

\footnotetext{
${ }^{9} \mathrm{~A}$ set of qualifications taken at the end of secondary schooling at age 16 .

${ }^{10}$ The Office for Standards in Education carries out inspections of all schools at roughly three-year intervals, and awards headline grades: Outstanding; Good; Requires improvement; Special measures.
} 
analogy to its conclusion by comparing the estimated weighting function to the rational benchmark under the full model, $\delta=1$, as this comparison would be too sensitive to model assumptions. Rather, estimates of $\delta$ are used to make qualitative comparisons between decision makers, and between decision contexts (list slots) for each decision maker. That is, the model estimates differences in the degree of admission-regarding preferences without pinning down how a given estimate of $\delta$ translates into comparative rationality or accuracy of expectations. The welfare estimates introduced in the next section allow objective comparisons of the outcomes of decision-making to be made which do not rely on estimates of $\delta$.

\section{$6 \quad$ Estimating welfare counterfactuals}

Current UK education policy relating to inequalities of access to good schools focusses on the geographical distribution of households and schools, and presupposes the existence of "cold spots": areas without good schools within a commutable distance (Department for Education 2016). The uneven distribution of good schools is one possible explanation for the observed differences in the proportion accepted into their first choice school. There are two additional competing explanations: first, differences in preferences and differences in strategy may mean that some demographics, minority ethnicities, for instance, are more likely to apply to popular schools, and less likely to use private information about chances of admission to avoid congested schools; second, the details of admission policies may lead to structural inequality in chances of admission.

It is possible that all three factors contribute to observed patterns of sorting and unequal headline admission statistics. It is also possible that, underlying the headline admission statistics, there is no actual difference in ordinal welfare between different demographic groups. For example, it may be the case that some families strategically edit their choice sets, so that their stated first choice is not actually their most preferred school, whereas other families truthfully report their preferences.

To examine the relative contribution of geography, admissions rules, and strategy/preferences, I compute expected welfare under three scenarios. I work with the expectations of log utilities rather than the expectations of Cobb-Douglas utilities, as the expectation of an exponentiated Extreme Value type I random variable is infinite. Log utilities are scaled by $\beta_{D(i)}$, so that $\log$ utilities are on the scale of $\log$ distance (in $\mathrm{km}$ ). Levels of utility have no direct economic meaning, and cannot be compared between groups with different preference functions, as the level of utility is only defined up to a constant that depends on preferences. However, differences of log utilities can be compared, and are equivalent to log ratios of distance. For example, a log welfare difference of 0.69 implies that the welfare difference is equivalent to having to travel approximately twice as far. A population-averaged preference function is also estimated, which imposes uniform preferences on all demographic groups, and allows direct welfare comparisons to be made. 
First, I estimate the expected utility of families' choice sets, ignoring capacity constraints, as

$$
W_{A}=\frac{1}{I} \sum_{i=1}^{I} E_{\epsilon}\left[\log \max _{j \in J} u_{i j} \mid R_{i}, \boldsymbol{x}, \boldsymbol{d}_{i},(\beta, \gamma)_{D(i)}\right]=\frac{1}{I} \sum_{i=1}^{N} E_{\epsilon}\left[\max _{j \in J} \log u_{i j} \mid R_{i}, \boldsymbol{x}, \boldsymbol{d}_{i},(\beta, \gamma)_{D(i)}\right] .
$$

This represents the average quality of the local school market, irrespective of whether the child can access it, and takes account of direct disutility from distance, but not the effect of distance on chances of admission. A single sample from the joint posterior distribution of $(\beta, \gamma)_{D(i)}$ is drawn for each child, so that the population distribution of welfare incorporates posterior parameter uncertainty.

The distribution of $\boldsymbol{\epsilon}_{i}$ is conditioned upon a family's rank-order list $R_{i}$ in the following way: although, under constrained lists, it may no longer be optimal to truthfully report all of one's preferences, it is still a dominant strategy to include those schools which are included in the list, in order of true preference (Fack et al., 2015). I assume that decision makers do not play a dominated strategy, and therefore the distribution of unobservables must be such that the preference order between schools in the submitted rank-order list is respected. Note that this does not imply anything about preference ordering of schools not included in the list. For this reason, the simple analytical expression $E_{\epsilon}\left[\max _{j \in J} \log u_{i j}\right]=\log \sum_{j \in J} \exp \left(\mu_{i j}^{u}\right)$ cannot be used. Instead, I approximate the expectation by simulating draws from

$$
\epsilon \mid \mu_{i r_{1}}^{u}+\epsilon_{i r_{1}}>\cdots>\mu_{i r_{S}}^{u}+\epsilon_{i r_{S}}
$$

using a Gibbs sampler to sample from truncated EV1 distributions for schools included in $R_{i}$, and sampling from an unconstrained EV1 distribution otherwise.

The second welfare calculation characterises the welfare that a rational parent can achieve by submitting an optimal list, given the constrained rank-order lists and school admissions criteria, and is

$$
W_{B}=\frac{1}{I} \sum_{i=1}^{I} E_{\epsilon}\left[\log \max _{R^{\prime} \in \mathcal{R}} E_{L_{R^{\prime}}}\left[u_{i}\right] \mid \hat{\boldsymbol{\rho}}_{i}, R_{i}, \boldsymbol{x}, \boldsymbol{d}_{i},(\beta, \gamma)_{D(i)}\right]
$$

where

$$
E_{L_{R^{\prime}}}\left[u_{i}\right]=\hat{\rho}_{i r^{\prime}{ }_{1}} \exp \left(\mu_{i r_{1}^{\prime}{ }_{1}}+\epsilon_{i r_{1}^{\prime} 1}\right)+\sum_{s=2}^{S}\left[\prod_{w=1}^{s-1}\left(1-\hat{\rho}_{i r^{\prime}{ }_{w}}\right)\right] \hat{\rho}_{i r^{\prime}{ }_{s}} \exp \left(\mu_{i r_{s}^{\prime}{ }_{s}}+\epsilon_{i r_{s}^{\prime}{ }_{s}}\right)
$$

for some rank-order list $R^{\prime} . \hat{\boldsymbol{\rho}}_{i}$ are calculated using the average structural function and a single draw from the joint posterior distribution of $(\phi, \varphi, \Delta)$ for each child. The calculation of $\max _{R^{\prime} \in \mathcal{R}} E_{L_{R^{\prime}}}\left[u_{i}\right]$ uses the marginal improvement algorithm (Chade and Smith 2006) to calculate the optimal list, for each draw of $\epsilon$.

Finally I define the expected average welfare of the lists that were actually submitted by parents

$$
W_{C}=\frac{1}{I} \sum_{i=1}^{I} E_{\epsilon}\left[\log E_{L_{R_{i}}}\left[u_{i}\right] \mid \hat{\boldsymbol{\rho}}_{i}, R_{i}, \boldsymbol{x}, \boldsymbol{d}_{i},(\beta, \gamma)_{D(i)}\right]
$$


and the average expected welfare of the allocations that children received

$$
W_{D}=\frac{1}{I} \sum_{i=1}^{I} E_{\epsilon}\left[\log u_{i j_{i}} \mid R_{i}, \boldsymbol{x}_{j_{i}}, d_{i j_{i}},(\beta, \gamma)_{D(i)}\right]
$$

If admission probabilities are well-calibrated, $1 / I \sum_{i=1}^{I} E_{\epsilon}\left[\log u_{i j_{i}}\right]$ converges to $1 / I \sum_{i=1}^{I} E_{\epsilon}\left[E_{L_{R_{i}}}\left[\log u_{i}\right]\right] \leq$ $1 / I \sum_{i=1}^{I} E_{\epsilon}\left[\log E_{L_{R_{i}}}\left[u_{i}\right]\right]$ so we should expect $W_{C}$ to be greater than $W_{D}$, with the size of the difference proportional to $\operatorname{Var}_{L_{R_{i}}}\left[u_{i}\right]$. For this reason, $W_{D}$ is used for analysis as it does not rely on the estimated admission probabilities.

These welfare calculations, and the differences between them, represent the relative contributions of geography, preferences/strategies, and admissions constraints to average welfare for different demographic groups. $W_{A}$ represents the welfare attributable to the geographic distribution of children and schools of different quality, before accounting for congestion. The difference between $W_{A}$ and $W_{B}$ represents the welfare loss attributable to capacity constraints, schools' admissions criteria and the design of the allocation mechanism (including constrained list length). The difference between $W_{B}$ and $W_{D}$ represents the welfare loss attributable to sub-optimal selection of rank-order lists. Care is needed in interpreting the gap between $W_{B}$ and $W_{D}$, since the difference also captures, to some extent, the quality of model fit. If some demographic group has more heterogeneous preferences that are less strongly predicted based on observables, then the difference between $W_{B}$ and $W_{D}$ may appear large. However, the variance of the estimate should also be larger so that inferences should still be valid.

\section{Parameter Estimates}

Estimates of all parameters are tabulated in the appendices. Figure 4 shows estimates of the Willingness to Travel for academic performance (proportion achieving five or more $\mathrm{A}^{*}-\mathrm{C}$ at GCSE) at $2.5 \mathrm{~km}$. The WTT is calculated as

$$
W T T_{D(i)}(d)=\frac{d \gamma_{D(i)}^{(A C 5)}}{\beta_{D(i)}}
$$

The estimates show that, with other demographics fixed, families of higher-KS2 children are always willing to travel further for a school with higher test scores than those of lower-KS2 children. In addition, minority ethnic families are willing to travel further for improvements in test scores than white families. For white families, willingness to travel is lower for Pupil Premium-eligible children. However, ethnic minority families' preferences, although varying strongly by KS2 attainment, vary very little by Pupil Premium status.

Table 1 shows large and precise estimates of $\delta_{s}$, the "strategy" parameter for families ranking slot $s$. I interpret estimates of $\delta$ with caution, noting that the parameter is more likely to absorb bias due to the approximate likelihood than other parameters. The magnitude of $\delta$ is sensitive to both the slot and the total number of schools ranked. $\delta$ is largest for those ranking only one school, and declines sharply as parents 


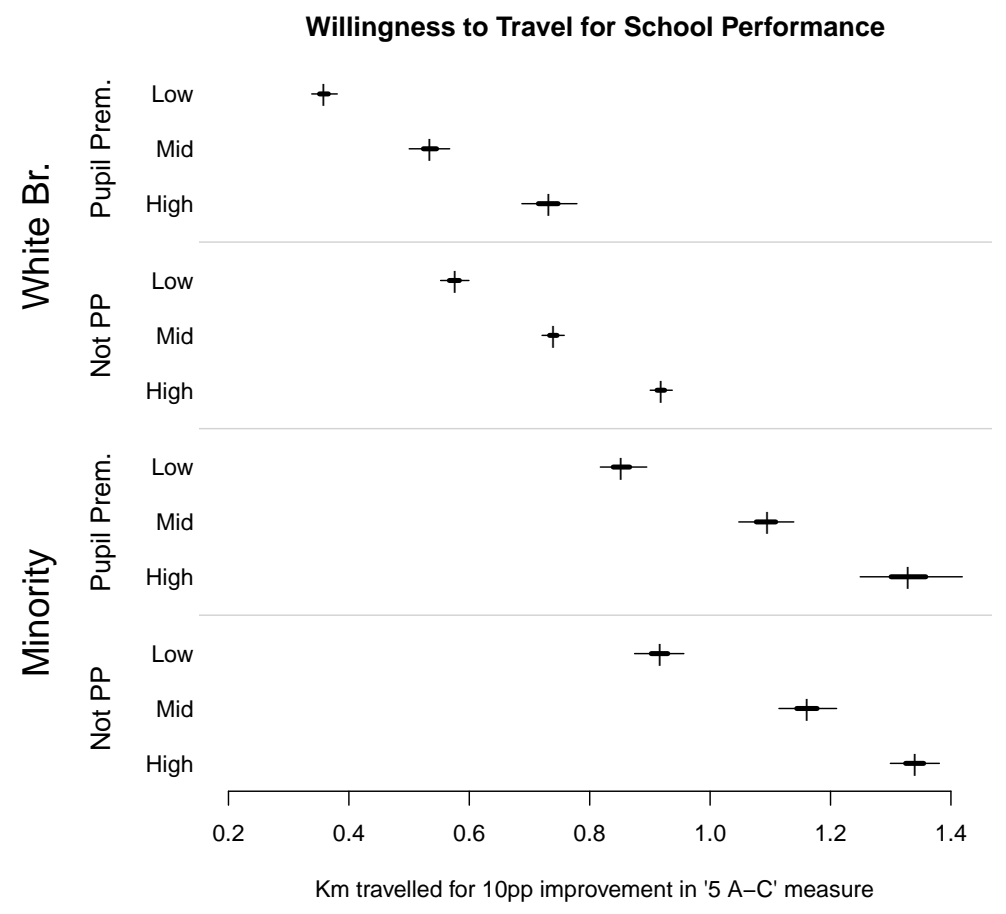

Figure 4: Willingness to Travel for performance by demographic.

Willingness to travel for improvement in a school performance indicator (\% achieving $5+\mathrm{A}^{*}$-C grades in GCSE exam), by pupil demographic group: two-way ethnicity; Pupil Premium status; and terciles of prior attainment at age 11 (Low/mid/High). The WTT is calculated at a fixed distance $d=2.5 \mathrm{~km}$ as $W T T=\left(d \gamma_{D(i)}^{A C 5}\right) / \beta_{D(i)}$. Vertical line shows posterior mean; thick line shows posterior inter-quartile range; thin line shows $95 \%$ credible interval.

rank more schools. For a given size of rank-order list, the parameter appears largest for the first preference, but does not appear to decline after the second preference. There may be a slight "insurance school" effect, where the parent has a larger $\delta$ for the school ranked last (i.e. " ${ }^{\text {st }}$ of 1 ", " $2^{\text {nd }}$ of 2 ", and " $3^{\text {rd }}$ of 3 "), although in general parents appear to take most account of probabilities in choosing their top-ranked school. There is a small but precisely-estimated increase in $\delta$ for parents applying for schools in LA's which allow them to rank no more than three schools (short-list LA's) compared to those allowing four to six. The estimated mean difference is $0.109(95 \% \mathrm{CI}=[0.076,0.139])$.

Figure 5 splits the estimates for one rank-position by demographic group. Three patterns are clear: $\delta$ is smaller for families eligible for Pupil Premium; it is larger for white families; and it is larger for parents of children with higher Key Stage 2 (end of primary school) attainment than for parents of children with lower KS2 attainment. It might be concerning if the patterns in $\delta$ qualitatively mirrored the patterns in $\beta$, the distance parameter. This might suggest that the model is just capturing preferences for distance which is correlated with probability of admission, which might be a concern even though the first stage equation contains identifying variation. However, the pattern of $\delta$ by KS2 attainment is counter to the pattern of $\beta$ by KS2 attainment (cf. Figure 16). The parents of higher-KS2 children appear to place more weight on admissions, but they place less weight on distance when choosing a school. Variation by demographic is not 
Table 1: Estimates of $\delta$ by number ranked and position

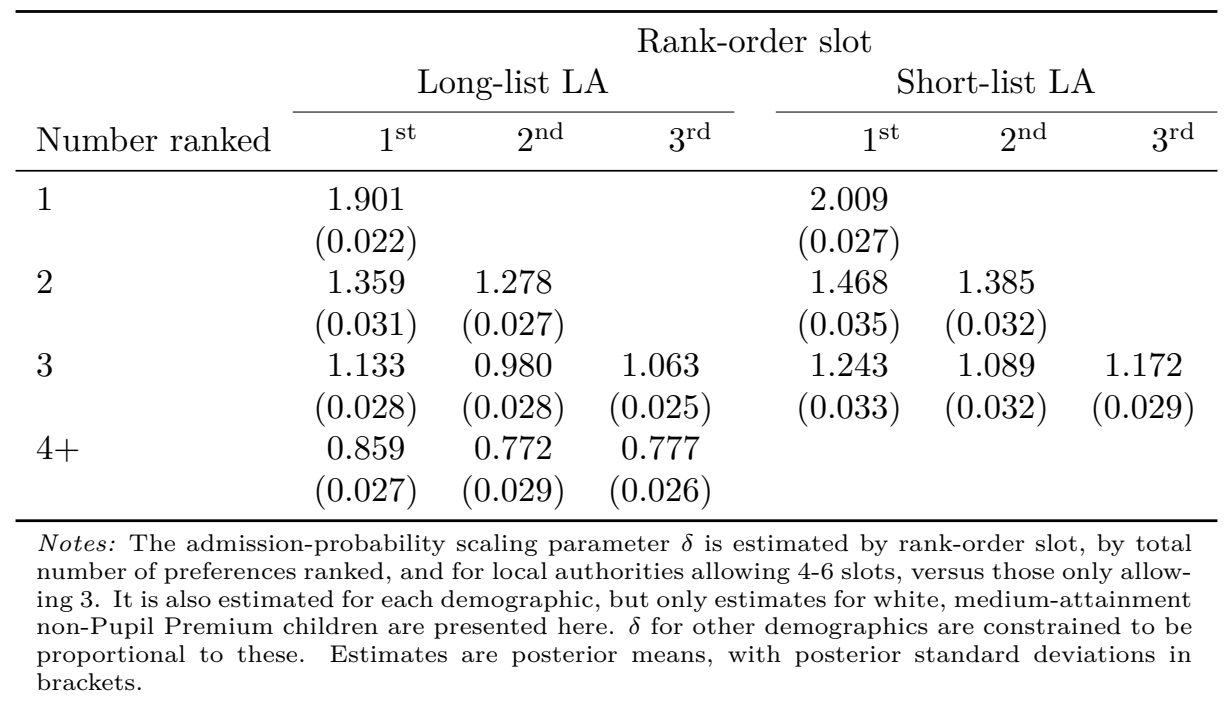

interacted with variation by rank-position or LA-type, so it is not possible to observe differences in $\delta$ across the full rank-order list by demographic group. The use of admission probabilities in decision-making appears to be dominated by white, non-Pupil Premium families, and particularly by more able children's families.

\section{Welfare estimates}

Figure 6 presents estimates of the national mean of welfare for each demographic group. These calculations are based on population-averaged estimates of the preference function, to allow between-group comparisons of welfare. $W_{A}$ is the welfare of the choice set before accounting for admission constraints. This quantity is about 0.15 higher for minority ethnic families, which is accounted for by residential sorting into urban areas. In general, $W_{A}$ is higher for families living in urban areas because the school market is more dense so disutility from travel is lower. Note that these results do not take account of variation in travel times. However, as the population is also more dense, these differences in utility are cancelled out by accounting for admissions $\left(W_{B}\right)$.

Figure 7 presents the same welfare calculations for two predominantly-urban regions - London and the West Midlands - for comparison. The variation in $W_{A}$ is much smaller, as the majority of families in these populations live in urban areas, but the variation in $W_{B}$ is accentuated. The pattern of $W_{B}$ in London echoes the pattern of $\delta$ shown in Figure 5; white, non-Pupil Premium families, and especially those with higher KS2 attainment, have higher admission-adjusted choice set utility than all other groups. The difference, for a high-KS2, non-Pupil Premium child is approximately 0.1, equivalent to a travel difference of $11 \%$. There is no mechanistic reason why this should be the case, since the strategy parameter is not used in the welfare calculations. In the West Midlands, $W_{B}$ for minority ethnic, Pupil Premium eligible families is around 0.3 
Estimates of admission-consciousness parameter $\delta$

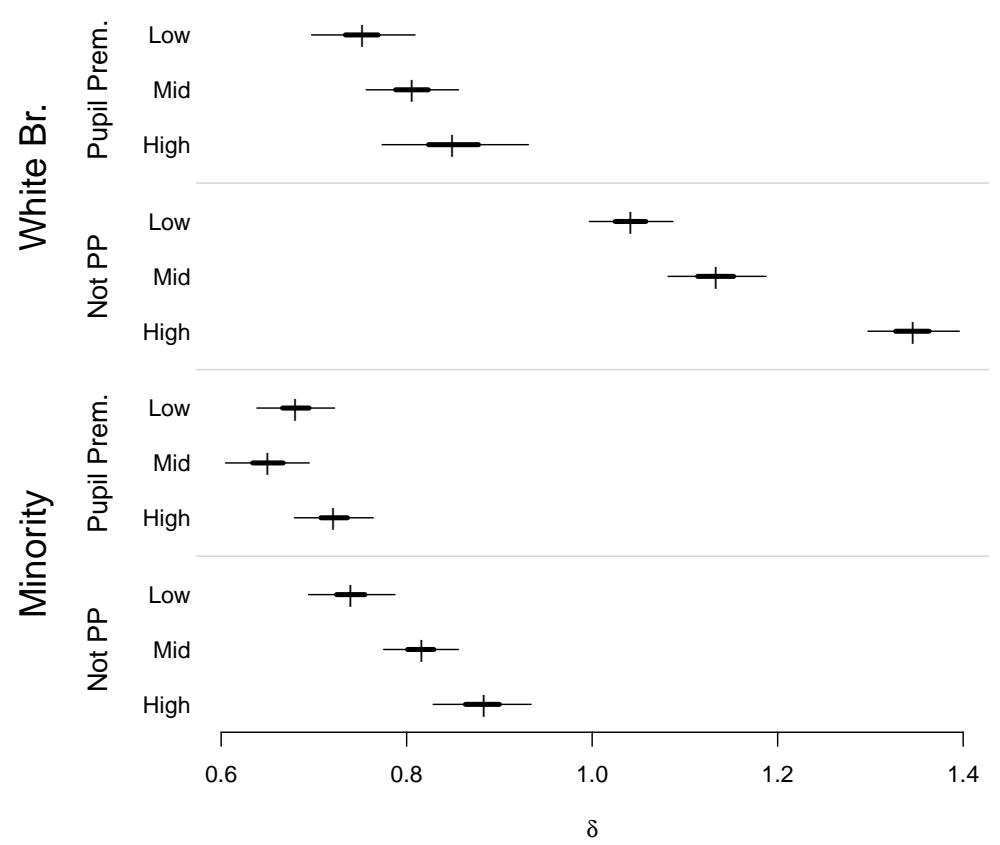

Figure 5: Estimates of $\delta$ by demographic

Estimates of strategy parameter $\delta$ for slot $s=1$ for parents ranking four or more schools, by pupil demographic group: ethnicity; Pupil Premium status; and terciles of prior attainment at age 11 (Low/mid/high). Vertical line shows posterior mean; thick line shows posterior inter-quartile range; thin line shows $95 \%$ credible interval.

lower than for white, non-Pupil Premium eligible families. This is equivalent to travelling about $35 \%$ further. Welfare differences are further analysed in Figure 8. These show that nationally, the welfare loss due to admission constraints, $W_{A}-W_{B}$, is a little larger than 0.2 for white families, and almost 0.4 for minority ethnic families, especially those eligible for Pupil Premium. The further welfare loss from not choosing the optimal list, $W_{B}-W_{D}$, is even larger, and the gap between white and minority ethnic families is also greater. Pupil Premium eligible, minority ethnic families have the largest loss in welfare due to sub-optimal choice, and non-Pupil Premium eligible, high-KS2, white families have the smallest loss in welfare due to sub-optimal choice. Figures 9 and 10 present these estimates for all English regions. 


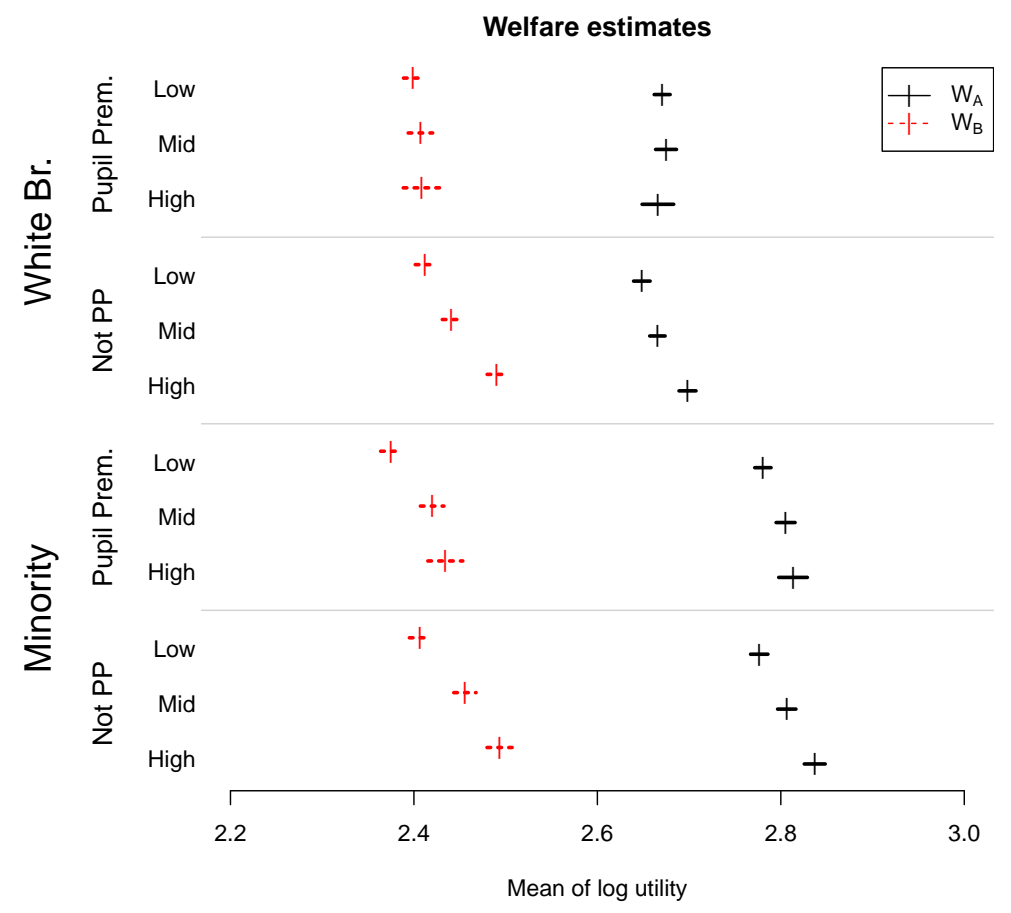

Figure 6: Welfare by demographic

Estimated average welfares $W_{A}$ and $W_{B}$, using a uniform preference function to allow comparisons between groups. $W_{A}$ is the $\log$ utility of the choice set, before accounting for capacity constraints. $W_{B}$ is the log utility of the choice set (i.e. the expected optimal utility that can be obtained), accounting for capacity constraints. Intervals are $1.96 \times \frac{s d}{\sqrt{I}}$. 

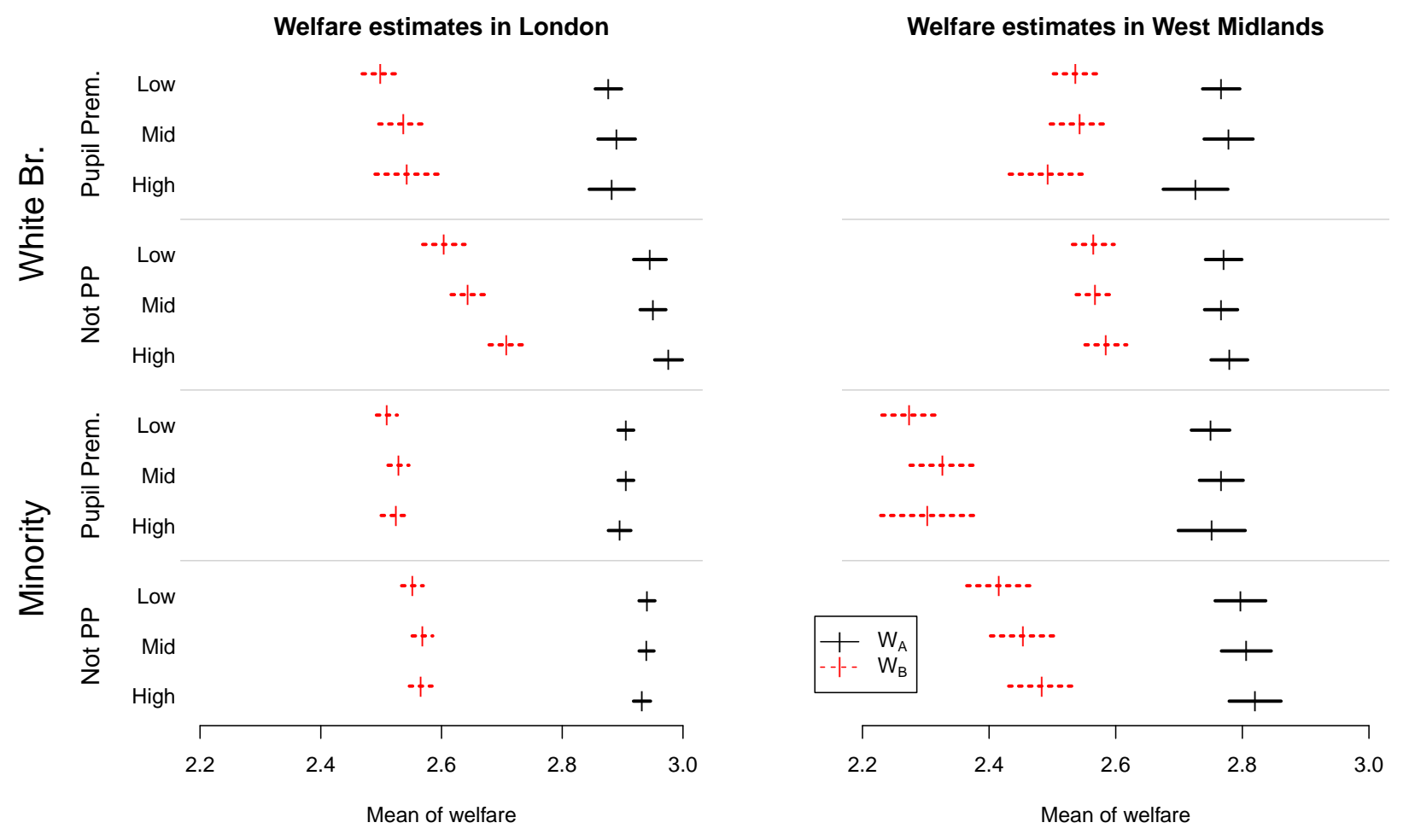

Figure 7: Welfare by demographic for London and West Midlands

Comparison of average welfare in two English regions: London and West Midlands (the other regions are plotted in the appendix). Both of these regions are predominantly urban and this controls for the urban/rural sorting of demographics that primarily affects estimates of $W_{A}$. In these plots the variation in $W_{A}$ is attenuated, revealing variation in $W_{B}$. Intervals are $1.96 \times \frac{\hat{s d}}{\sqrt{I}}$. 


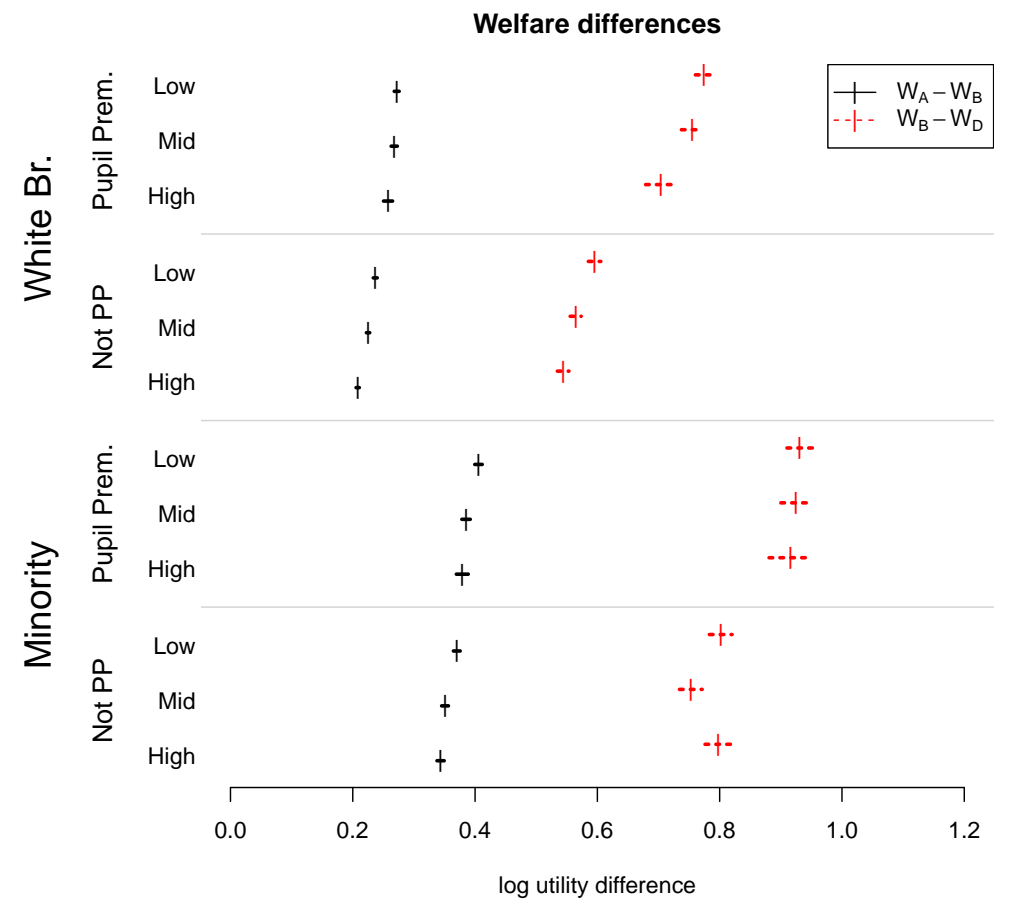

Figure 8: Estimates of log-welfare differences

Loss from capacity constraints: $W_{A}-W_{B}$; and loss from sub-optimal list choice: $W_{B}-W_{D}$. Differences are interpretable as $\log$ distance ratios. For example, $W_{A}-W_{B}=0.69$ would imply a utility difference equivalent to having to travel roughly twice as far to school. Intervals are $1.96 \times \frac{s d}{\sqrt{I}}$. 


\section{Conclusion}

I have modelled parental preferences and school ranking functions with the intention of understanding the apparent inequality in outcomes of the secondary school admissions process for children from different demographic groups, especially with respect to the apparent 'ethnic gap' in chances of admission. Results from the welfare analysis indicate that there is a real welfare gap underlying the ethnic admissions gap, and that both the design of the admissions system (and admissions priority rules) and differences in parental decision-making play a role.

With regards to structural factors, Weldon (2018) presents evidence that chances of admission to oversubscribed schools is lower for both ethnic minority and low income children after accounting for distance to the school, and that most of this difference can be accounted for by church schools' selection practices. That study controls away residential differences, so it is not possible to say what proportion of admissions inequality is due to 'selection by house prices'.

With regards to behavioural differences between white and minority ethnic groups, some large and striking differences in estimated trade-offs between school qualities, proximity, and chances of admission have been estimated. On average, parents of minority ethnicities appear to place more emphasis on school test scores and Ofsted scores, and less emphasis on measures of peers (\% eligible for Pupil Premium), when choosing a school. Lower-KS2 minority ethnic children's parents are also more likely to apply to grammar schools (cf. Figure 20) than lower-KS2 white parents. Taken together with the descriptive evidence, these results consistently indicate a difference in preferences for academic performance. Minority ethnic parents seem to value academics more, and make more aspirational educational choices.

In interactions between ethnicity and Pupil Premium status, the results indicate that the income gap in preferences for educational quality (documented by Bertoni, Gibbons, and Silva (2017), Allen, Burgess, and McKenna (2014), Burgess et al. (2015) and Deming et al. (2014) among others) is less evident for minority ethnic children than it is for white children. Low income minority ethnic parents appear to value test score performance and Ofsted grades almost as much as non-low income minority ethnic parents.

Results for the strategy parameter, $\delta$ suggest that white, non-low income parents are much more aware of, or give much more heed to, their children's chances of acceptance when choosing which schools to list, when compared to both low income whites and minority ethnicities. That this relationship does not mirror the estimates for willingness to travel for school quality, suggests that preferences for educational quality are independent of admissions-consciousness. In fact, estimates of $\delta$ are almost a mirror image of estimates of peer preferences (\% eligible for PP; cf. Figure 18). White, non-low income parents appear to take note of both chances of admission, and the socio-economic composition of the school. They appear to value more affluent schools with a higher chance of admission, and to give secondary emphasis to academic performance.

The parallel between admission-consciousness and peer preferences might suggest a story whereby 'sharp- 
elbowed middle class' parents are, in fact, motivated primarily by fear of negative social mobility, to make 'safe' choices characteristic of loss aversion. The theme of loss aversion by advantaged groups has been explored in the sociological literature on school choice (Breen and Goldthorpe, 1997; Leonardi, 2007; Belzil and Leonardi, 2013). In the economics literature risk aversion has been analysed in a couple of recent papers (Chen and Pereyra, 2017; Klijn et al., 2013). In contrast, minority ethnic parents (both low income and non-low income) make more 'risky', aspirational choices characteristic of optimism.

However, the welfare analysis suggests that, if deliberate, minority ethnic parents' aspirational strategy may be suboptimal. The welfare loss between the optimal report and the actual allocation is larger for minority ethnic children ${ }^{11}$ This is in spite of the fact that they are more likely to take the sensible strategy of filling their rank-order lists.

If not deliberate, the variation in admission-consciousness, and in admission welfare outcomes, may be explained by information differentials between demographic groups (Bonal et al., 2017; Kloosterman and Troyan, 2018). That is, white, non-poor parents may be better at accurately assessing admission probabilities to oversubscribed schools. English secondary school admissions are complex, and there are a number of areas where contextual information may give an advantage: faith school admissions; grammar schools; catchment areas; and the design of the allocation mechanism itself for example. Given that minority ethnic parents are aspirational and evidently wish to optimise their chances of accessing a good school (for example by ranking more schools, on average, than white parents) an explanation based on information asymmetries seems more plausible than trying to rationalise group differences in terms of deliberate attitudes to risk.

If non-white and low income parents are not choosing optimally in the current admissions system, what is the best way to improve outcomes for these groups? One option would be to implement policies designed to 'nudge' parents towards more strategic choices. However, it would be easier, and more equitable, to redesign the admissions system to remove the incentives to choose strategically, and at the same time to remove the structural inequalities in access that differentially affect minority ethnic and low income groups. The simplest such policy would be to increase, or remove entirely, the maximum number of schools parents may list. Other effective interventions would probably focus on the design of admission priority rules, and reducing schools' autonomy to set and implement their own admission policies.

The analysis in this paper has brought to light striking and welfare-relevant behavioural phenomena that had hitherto been underappreciated. To obtain a thorough understanding of these phenomena will require more than data analysis alone. Rather, further data analysis, in combination with social and economic theory and qualitative research, may provide useful insights.

\footnotetext{
${ }^{11}$ Welfare estimates are not a function of the admission-consciousness parameter, $\delta$, and therefore provide independent evidence of differences in strategy.
} 


\section{References}

Abdulkadiroğlu, A., Agarwal, N., and Pathak, P. (2017). The Welfare Effects of Coordinated Assignment: Evidence from the New York City high school match. The American Economic Review, 107(12):3635-3689.

Abdulkadiroğlu, A. and Sönmez, T. (2003). School Choice: A mechanism design approach. American Economic Review, 93(3):729-747.

Agarwal, N. and Somaini, P. (2018). Demand Analysis using Strategic Reports: An application to a school choice mechanism. Econometrica, 86(2):391- 444 .

Ajayi, K. (2013). School Choice and Educational Mobility: Lessons from Secondary School Applications in Ghana. Working Paper.

Ajayi, K. and Sidibé, M. (2016). An Empirical Analysis of School Choice Under Uncertainty. Working Paper.

Azevedo, E. M. and Leshno, J. D. (2016). A supply and demand framework for two-sided matching markets. Journal of Political Economy, 124(5):1235-1268.

Belzil, C. and Leonardi, M. (2013). Risk aversion and schooling decisions. Annals of Economics and Statistics, $(111 / 112): 35-70$.

Bertoni, M., Gibbons, S., and Silva, O. (2017). School choice during a period of radical school reform: evidence from the academy programme. IZA discussion paper.

Blundell, R. W. and Powell, J. L. (2004). Endogeneity in semiparametric binary response models. The Review of Economic Studies, 71(3):655-679.

Bonal, X., Verger, A., and Zancajo, A. (2017). Making poor choices? demand rationalities and school choice in a chilean local education market. Journal of School Choice, 11(2):258-281.

Breen, R. and Goldthorpe, J. H. (1997). Explaining educational differentials: Towards a formal rational action theory. Rationality and Society, 9(3):275-305.

Burgess, S., Greaves, E., and Vignoles, A. (2017). Understanding Parental Choices of Secondary School in England using National Administrative Data. University of Bristol Discussion Paper no. 17/689.

Burgess, S., Greaves, E., Vignoles, A., and Wilson, D. (2015). What Parents Want: School Preferences and School Choice. The Economic Journal, 125(587):1262-1289.

Calsamiglia, C., Fu, C., and Güell, M. (2014). Structural Estimation of a Model of School Choices: The Boston mechanism vs. its alternatives. FEDEA Working Paper no. 2014-21. 
Calsamiglia, C. and Güell, M. (2018). Priorities in school choice: The case of the Boston mechanism in Barcelona. Journal of Public Economics, 163:20-36.

Calsamiglia, C., Haeringer, G., and Klijn, F. (2010). Constrained school choice: An experimental study. The American Economic Review, 100(4):1860-1874.

Cantillon, E. (2017). Broadening the market design approach to school choice. Oxford Review of Economic Policy, 33(4):613-634.

Chade, H. and Smith, L. (2006). Simultaneous search. Econometrica, 74(5):1293-1307.

Chanfreau, J., Tanner, E., Callanan, M., Laing, K., Paylor, J., Skipp, A., and Todd, L. (2015). Out of school activities: Understanding who does what. Natcen social research briefing.

Chen, L. and Pereyra, J. (2017). Self-selection in school choice. Working paper.

Coldron, J., Tanner, E., Finch, S., Shipton, L., Wolstenholme, C., Willis, B., Demack, S., and Stiell, B. (2008). Secondary school admissions. Technical report, Department for Children, Schools and Families.

Dale, S. B. and Krueger, A. B. (2002). Estimating the payoff to attending a more selective college: an application of selection on observables and unobservables. Quarterly Journal of Economics, 117:1491-1527.

Deming, D. J., Hastings, J. S., Kane, T. J., and Staiger, D. O. (2014). School choice, school quality, and postsecondary attainment. American Economic Review, 104(3):991-1013.

Department for Education and Skills (2007). School Admissions Code. Available at http://www.education.gov.uk.

Dubin, J. A. and McFadden, D. L. (1984). An econometric analysis of residential electric appliance holdings and consumption. Econometrica, 52:345-362.

Dustmann, C., Machin, S., and Schoenberg, U. (2010). Ethnicity and educational achievement in compulsory schooling. Economic Journal, 120(546):272.

Fack, G., Grenet, J., and He, Y. (2015). Beyond Truth-Telling: Preference estimation with centralized school choice. Working Paper.

Gale, D. and Shapley, L. (1962). College admissions and the stability of marriage. The Americal Mathematical Monthly, 69:9-15.

Gallego, F. and Hernando, A. (2009). School Choice in Chile: Looking at the Demand Side. Documentos de trabajo 356, instituto de economia. pontificia universidad católica de chile.

Gibbons, S. and Machin, S. (2006). Paying for primary schools: Admission constraints, school popularity or congestion? The Economic Journal, 116(510):C77-C92. 
Gibbons, S., Machin, S., and Silva, O. (2013). Valuing School Quality using Boundary Discontinuities . Journal of Urban Economics, 75:15-28.

Haeringer, G. and Klijn, F. (2009). Constrained School Choice. Journal of Economic Theory, 144:1921-1947.

Heckman, J. (1979). Sample selection bias as a specification error. Econometrica, 47(1):53-61.

Kahneman, D. and Tversky, A. (1979). Prospect theory: An analysis of decision under risk. Econometrica, $47(2): 263-91$.

Klijn, F., País, J., and Vorsatz, M. (2013). Preference intensities and risk aversion in school choice: a laboratory experiment. Experimental Economics, 16(1):1-22.

Kloosterman, A. and Troyan, P. (2018). School choice with asymmetric information: Priority design and the curse of acceptance. Working paper.

Leonardi, M. (2007). Do parents risk aversion and wealth explain secondary school choice? Giornale degli Economisti e Annali di Economia, 66 (Anno 120)(2):177-206.

Luflade, M. (2018). The Value of Information in Centralized School Choice Systems. Working paper, Duke University.

Pathak, P. a. and Sönmez, T. (2013). School admissions reform in Chicago and England: Comparing mechanisms by their vulnerability to manipulation. American Economic Review, 103(1):80-106.

Prelec, D. (1998). The probability weighting function. Econometrica, 66(3):497-527.

Quiggin, J. (1982). A theory of anticipated utility. Journal of Economic Behavior and Organization, 3(4):323 $-343$.

Stokes, L., Rolfe, H., Hudson-Sharpe, N., and Stevens, S. (2015). A compendium of evidence on ethnic minority resilience to the effects of deprivation on attainment. Department for education research report.

Weldon, M. (2018). Secondary School Choice and Selection: Evidence from new national preferences data. Department for education research report.

West, A., Hind, A., and Pennell, H. (2004). School admissions and 'selection' in comprehensive schools: policy and practice. Oxford Review of Education, 30:349-369.

Wilson, D., Burgess, S., and Briggs, A. (2011). The dynamics of school attainment of england's ethnic minorities. Journal of Population Economics, 24(2):681-700. 


\section{Omitted tables and figures}

Table 2: \% admitted to first-choice school in 2014

\begin{tabular}{lrrrr}
\hline & England & London & Birmingham & Manchester \\
\hline White & 93 & 84 & 89 & 93 \\
Black & 73 & 68 & 72 & 77 \\
S. Asian & 75 & 71 & 68 & 80 \\
Other & 80 & 72 & 78 & 82 \\
not FSM & 89 & 75 & 80 & 89 \\
FSM & 86 & 73 & 80 & 88 \\
All & 88 & 74 & 80 & 89 \\
\hline * Eligible for Free School Meals. & & &
\end{tabular}

Table 3: \% ranking each number of schools in 2014

\begin{tabular}{lrrrrrr}
\hline \# ranked & White & Black & S. Asian & Other & not FSM & FSM \\
\hline London & & & & & & \\
1 & 16 & 8 & 9 & 11 & 10 & 13 \\
$2-3$ & 45 & 31 & 35 & 37 & 36 & 39 \\
$4-6$ & 39 & 61 & 56 & 52 & 54 & 48 \\
Birmingham & & & & & & \\
1 & 32 & 19 & 17 & 25 & 23 & 30 \\
$2-3$ & 51 & 43 & 37 & 44 & 47 & 43 \\
$4-6$ & 18 & 37 & 46 & 30 & 30 & 28 \\
Manchester & & & & & & \\
1 & 38 & 25 & 28 & 34 & 33 & 40 \\
$2-3$ & 54 & 60 & 57 & 52 & 56 & 53 \\
$4-6$ & 8 & 14 & 15 & 14 & 11 & 7 \\
\hline
\end{tabular}


Table 4: Sample descriptives for the preference estimation

\begin{tabular}{|c|c|c|c|c|c|}
\hline & $\mathrm{N}$ & $\%$ & N ranks & Avg dist. (km) & $\operatorname{Avg} \% \mathrm{AC}^{*}$ \\
\hline All & 84,991 & 100 & 175,383 & 3.65 & 62.4 \\
\hline \multicolumn{6}{|l|}{ Ethnicity } \\
\hline White & 57,940 & 68 & 112,291 & 3.69 & 61.4 \\
\hline Minority & 27,051 & 32 & 63,092 & 3.57 & 64.6 \\
\hline \multicolumn{6}{|l|}{ Pupil Premium } \\
\hline Not PP. & 59,475 & 70 & 123,727 & 3.89 & 64.4 \\
\hline Pupil Prem. & 25,516 & 30 & 51,656 & 3.09 & 58.0 \\
\hline \multicolumn{6}{|l|}{ KS2 attainment } \\
\hline KS2: Low & 31,448 & 37 & 62,090 & 3.21 & 58.6 \\
\hline KS2: Mid & 30,217 & 36 & 62,486 & 3.65 & 62.6 \\
\hline KS2: High & 23,326 & 27 & 50,807 & 4.24 & 67.4 \\
\hline \multicolumn{6}{|l|}{ Number ranked $^{\dagger}$} \\
\hline One & 27,287 & 32 & 27,287 & 2.84 & 59.8 \\
\hline Two & 18,376 & 22 & 35,718 & 3.63 & 61.4 \\
\hline Three & 21,722 & 26 & 62,903 & 3.88 & 62.1 \\
\hline Four & 8,144 & 10 & 23,303 & 4.75 & 66.8 \\
\hline Five & 3,664 & 4 & 9,631 & 3.73 & 65.0 \\
\hline Six & 5,798 & 7 & 16,541 & 4.99 & 71.9 \\
\hline \multicolumn{6}{|l|}{ Region } \\
\hline East & 6,241 & 7 & 13,859 & 5.09 & 63.7 \\
\hline East Midlands & 5,453 & 6 & 9,551 & 3.41 & 62.4 \\
\hline London & 17,729 & 21 & 44,105 & 3.44 & 68.5 \\
\hline North East & 4,503 & 5 & 8,586 & 2.59 & 56.9 \\
\hline North West & 8,848 & 10 & 18,292 & 3.40 & 60.4 \\
\hline South East & 12,591 & 15 & 27,318 & 5.06 & 66.0 \\
\hline South West & 5,794 & 7 & 10,142 & 4.15 & 61.6 \\
\hline West Midlands & 9,861 & 12 & 17,100 & 2.92 & 58.1 \\
\hline Yorkshire & 13,894 & 16 & 26,319 & 2.80 & 57.5 \\
\hline
\end{tabular}

Notes: The discrete choice model was estimated using a clustered choice-based sample, sampled from 35 clusters of 10 or 11 schools. ${ }^{*} \%$ of children achieving five or more $\mathrm{A}^{*}-\mathrm{C}$ grades at GCSE. ${ }^{\dagger}$ Only up to three ranked preferences were used in estimation for each person. 
Table 5: Original ethnic coding and the codings used in this report, with counts

\begin{tabular}{lllr}
\hline Original & Four-way & Two-way & Count \\
\hline Asian: Pakistani & SOUTHASIAN & Minority & 24,335 \\
Asian: Indian & SOUTHASIAN & Minority & 14,434 \\
Asian: Bangladeshi & SOUTHASIAN & Minority & 10,103 \\
Asian: Other & SOUTHASIAN & Minority & 8,640 \\
Mixed white/Asian & SOUTHASIAN & Minority & 5,921 \\
Black African & BLACK & Minority & 18,857 \\
Black Caribbean & BLACK & Minority & 8,019 \\
Mixed white/Black Caribbean & BLACK & Minority & 7,790 \\
Black other & BLACK & Minority & 3,960 \\
Mixed white/Black African & BLACK & Minority & 3,060 \\
White other & OTHER & Minority & 26,026 \\
Mixed other & OTHER & Minority & 9,469 \\
Other & OTHER & Minority & 8,789 \\
Chinese & OTHER & Minority & 1,993 \\
White British & WHITE & White & 397,372 \\
White Roma & WHITE & White & 1,897 \\
White Irish & WHITE & White & 1,728 \\
White Irish Traveller & WHITE & White & 485 \\
Refused & & Missing & 2,260 \\
No Information & & Missing & 1,077 \\
\hline
\end{tabular}

Notes: The original codings are taken from the National Pupil Database. Counts are based on the 2013 cohort before removing missing values.

Table 6: Priority-revealing effects of rank-position on admission probability

\begin{tabular}{lllll}
\hline \multirow{4}{*}{ \# ranked } & \multicolumn{5}{c}{1} & \multicolumn{2}{c}{ Slot } & \multicolumn{1}{c}{3} & 4 \\
\hline 1 & 0 & & & \\
& & & & \\
2 & -1.451 & -2.225 & & \\
& $(0.026)$ & $(0.050)$ & & \\
3 & -1.688 & -2.875 & -2.969 & \\
4 & $(0.025)$ & $(0.036)$ & $(0.057)$ & \\
4 & -1.890 & -2.961 & -3.196 & -3.178 \\
$5+$ & $(0.029)$ & $(0.041)$ & $(0.060)$ & $(0.092)$ \\
5 & -2.286 & -3.271 & -3.711 & -3.867 \\
& $(0.029)$ & $(0.039)$ & $(0.052)$ & $(0.068)$ \\
\hline
\end{tabular}

Notes: Posterior log-odds estimates of the priority index function. Posterior means, posterior standard deviations in brackets. Log-odds of admission vary by how many schools were ranked in total (rows) and which slot the current school was listed at (columns). For example, the third column represents log-odds of admission for a child who has been rejected by the first and second preferences. 
Table 7: Admission index function estimates

\begin{tabular}{lcccccc}
\hline & Community & Academy & RC & CofE & Other & Grammar \\
\hline intercept & 1.650 & 1.579 & 2.355 & 2.162 & 2.776 & 0.477 \\
& $(0.040)$ & $(0.030)$ & $(0.051)$ & $(0.061)$ & $(0.108)$ & $(0.061)$ \\
KS2 & 0.017 & 0.131 & 0.070 & 0.134 & 0.381 & 1.092 \\
& $(0.024)$ & $(0.011)$ & $(0.021)$ & $(0.023)$ & $(0.076)$ & $(0.031)$ \\
Nearest school & 1.729 & 0.770 & -0.250 & 0.253 & 0.416 & 0.009 \\
& $(0.071)$ & $(0.032)$ & $(0.055)$ & $(0.055)$ & $(0.305)$ & $(0.067)$ \\
Pupil Premium & -0.214 & -0.351 & -0.710 & -1.029 & -1.076 & -0.905 \\
& $(0.057)$ & $(0.028)$ & $(0.050)$ & $(0.058)$ & $(0.526)$ & $(0.076)$ \\
Minority & -0.813 & -0.571 & -0.507 & -0.881 & -0.582 & -0.654 \\
& $(0.050)$ & $(0.022)$ & $(0.041)$ & $(0.043)$ & $(0.139)$ & $(0.037)$ \\
Minority $\times$ & 0.258 & 0.104 & 0.289 & 0.743 & 0.697 & 0.103 \\
PP. & $(0.081)$ & $(0.039)$ & $(0.069)$ & $(0.079)$ & $(0.544)$ & $(0.095)$ \\
\# grammars & 0.326 & 0.544 & 0.322 & 0.395 & 1.068 & 0.744 \\
listed & $(0.104)$ & $(0.027)$ & $(0.052)$ & $(0.067)$ & $(0.216)$ & $(0.023)$ \\
RC primary & & & 1.877 & & & \\
CofE primary & & & $(0.039)$ & & & \\
& & & & 0.618 & & \\
\hline Notes: Posto & & & & $(0.040)$ & & \\
\hline
\end{tabular}

Notes: Posterior log-odds estimates of the priority index function. Posterior means, posterior standard deviations in brackets. 

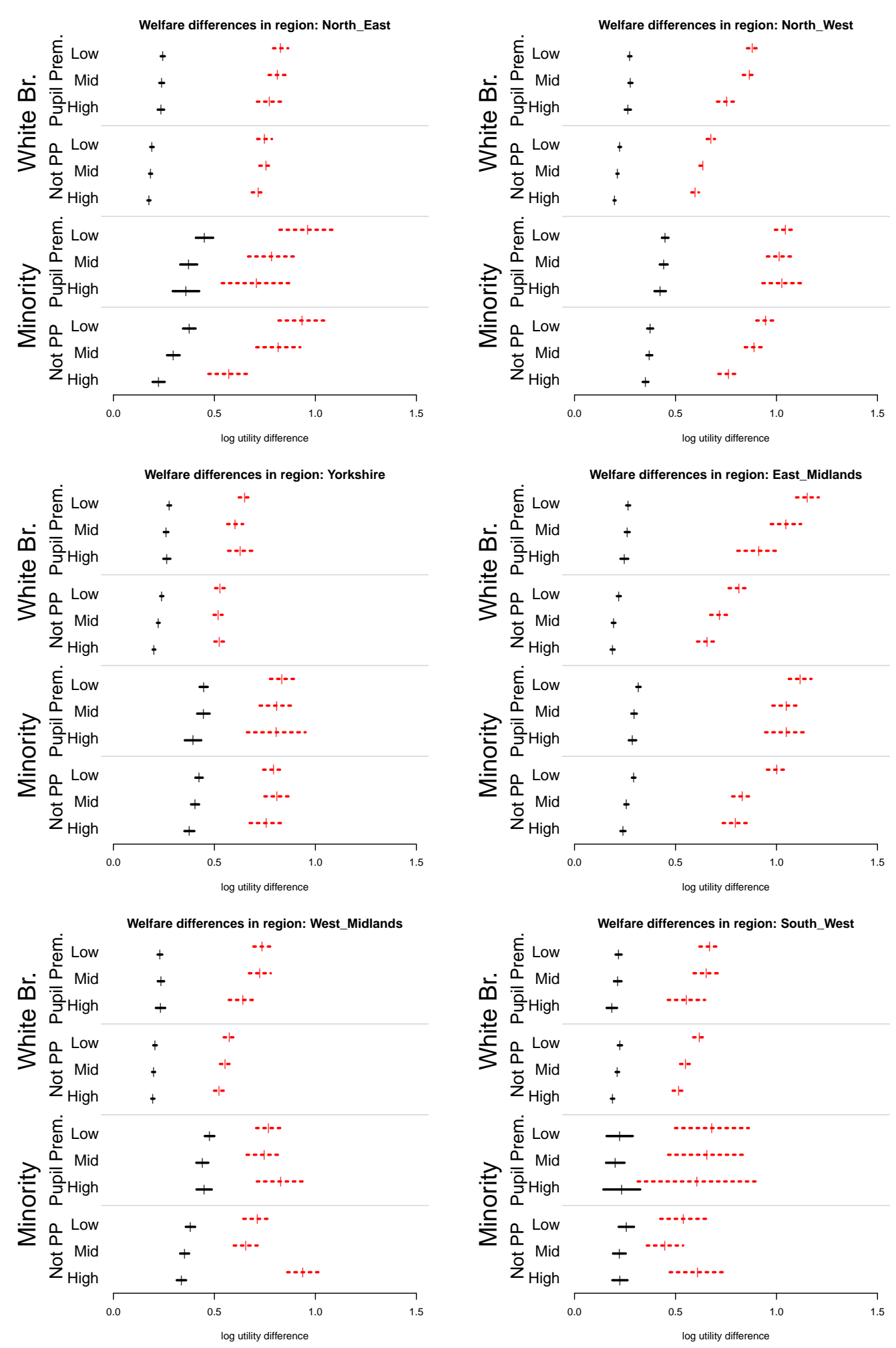

\begin{abstract}
$+\mathrm{W}_{\mathrm{A}}-\mathrm{W}_{\mathrm{B}}-+-\mathrm{W}_{\mathrm{B}}-\mathrm{W}_{\mathrm{D}}$
Figure 9: Estimates of log-welfare differences: loss from capacity constraints $-W_{A}-W_{B}$; and loss from sub-optimal list choice $-W_{B}-W_{D}$. Differences are interpretable as log distance ratios. For example, $W_{A}-W_{B}=0.69$ would imply a utility difference equivalent to having to travel roughly twice as far to school. Intervals are $1.96 \times \frac{\hat{s d}}{\sqrt{I}}$.
\end{abstract}



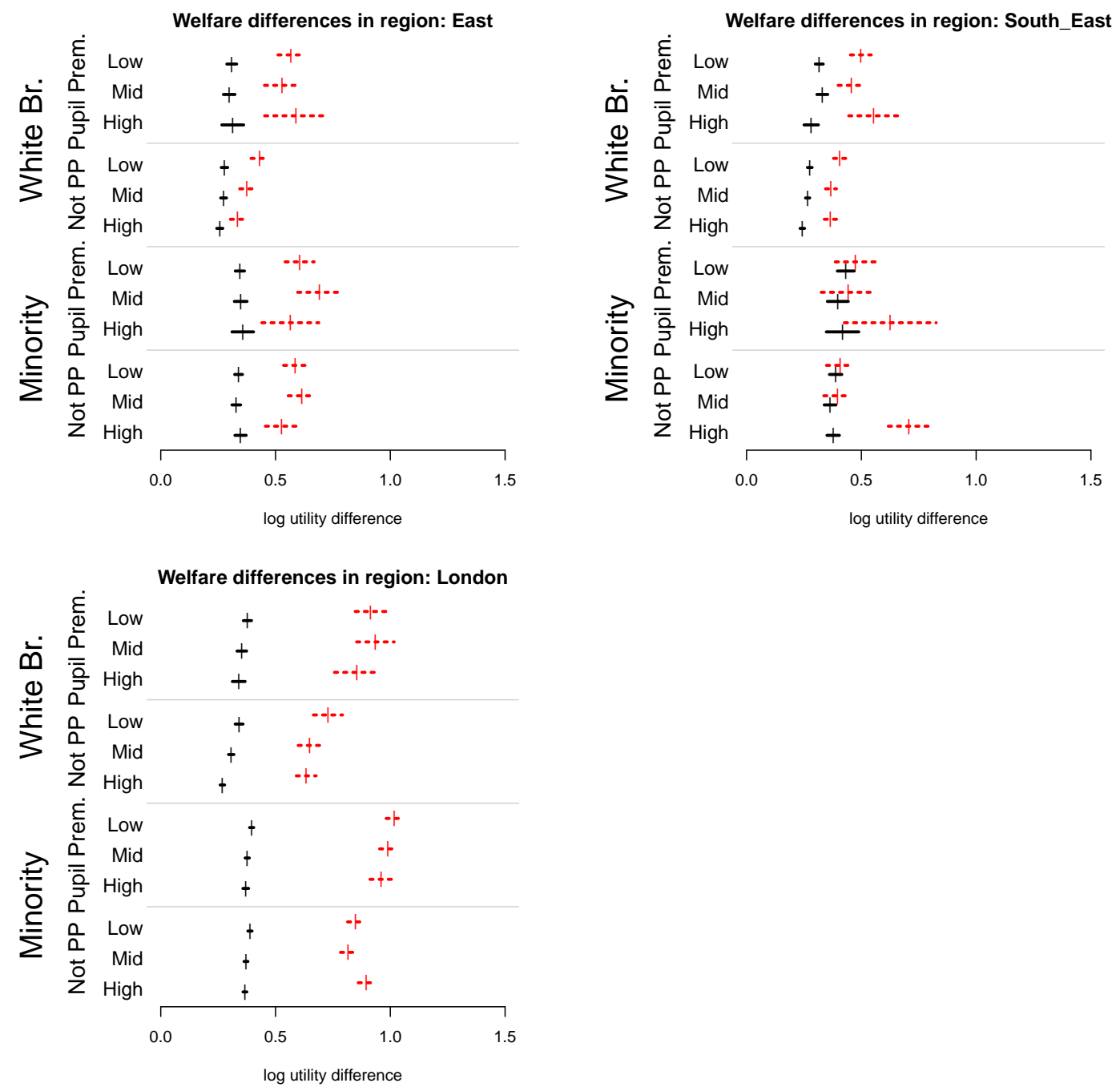$$
+W_{A}-W_{B}-\dashv-W_{B}-W_{D}
$$

Figure 10: Estimates of log-welfare differences: loss from capacity constraints $-W_{A}-W_{B}$; and loss from sub-optimal list choice $-W_{B}-W_{D}$. Differences are interpretable as log distance ratios. For example, $W_{A}-W_{B}=0.69$ would imply a utility difference equivalent to having to travel roughly twice as far to school. Intervals are $1.96 \times \frac{\hat{s d}}{\sqrt{I}}$.
} 
Mean AC5 of listed schools

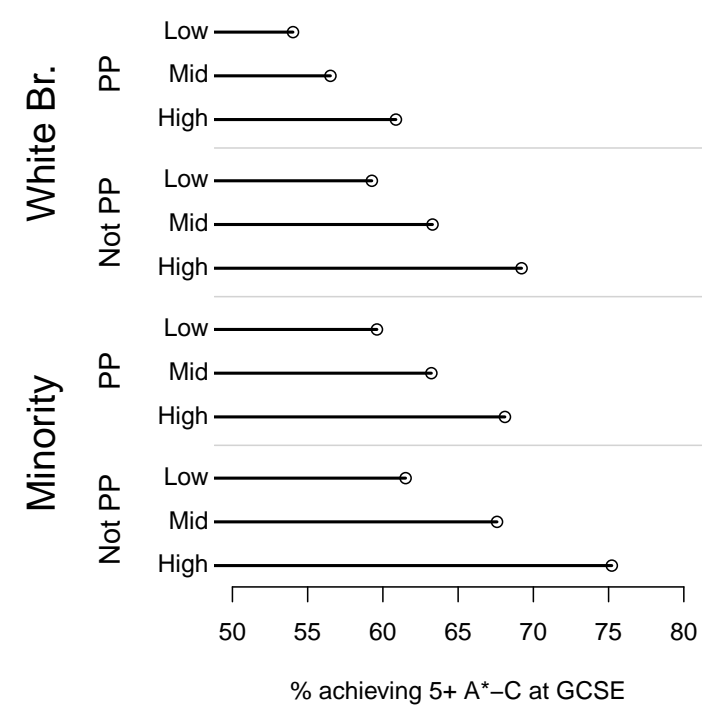

Mean AC5 for London

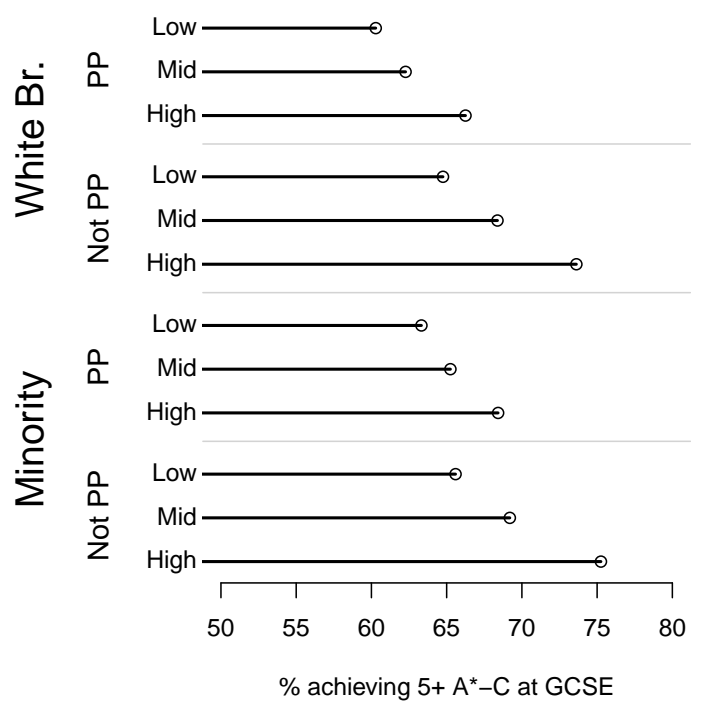

Figure 11: The mean test scores (\% achieving at least $5 A^{*}-C$ at GCSE) of listed schools by demographic. Higher ability children's families, and minority ethnic families, list higher-test-score schools. Pupil-Premiumeligible families list lower-test-score schools.
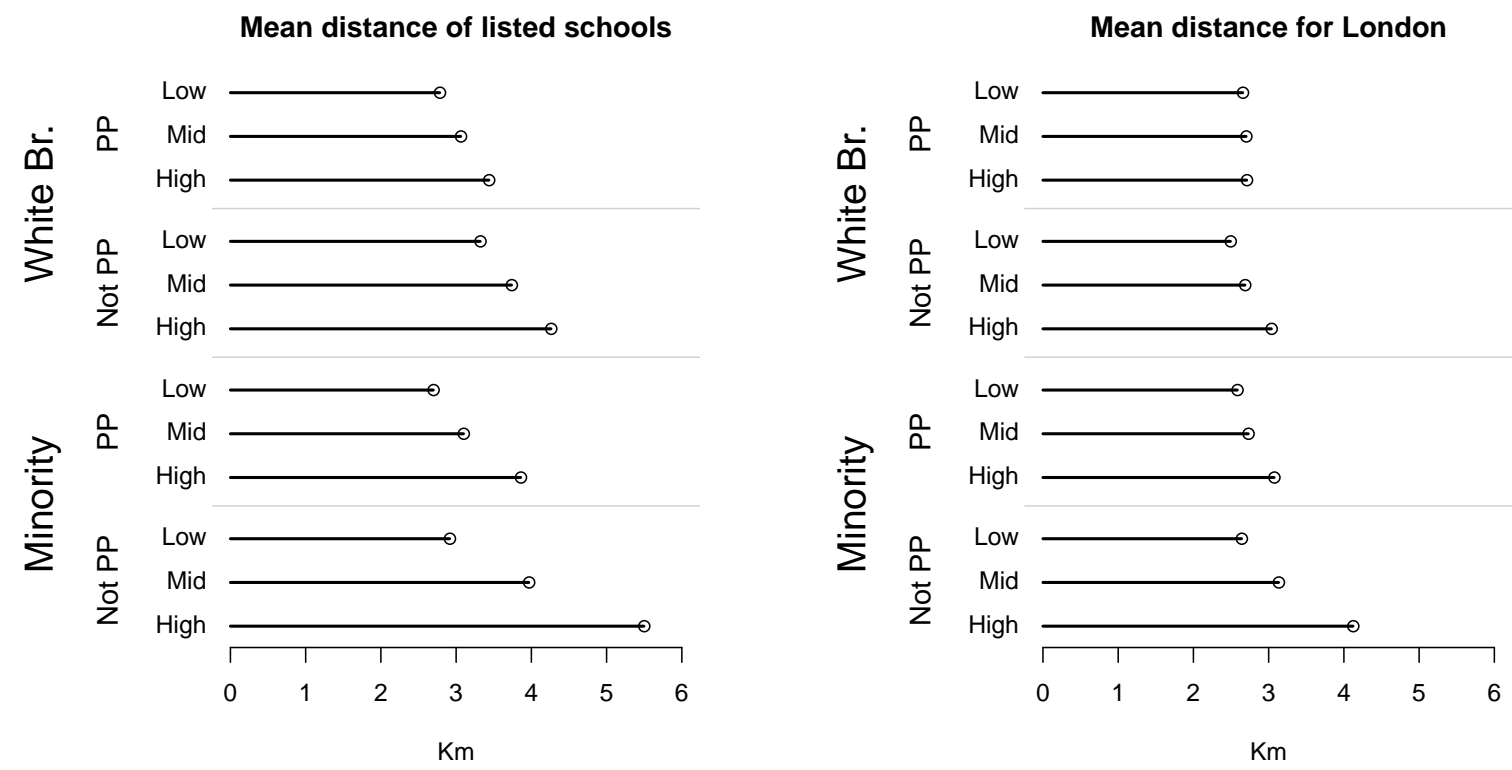

Figure 12: The mean distance in Km of listed schools by demographic. Higher ability children's families, and minority ethnic families, list more distant schools. Pupil-Premium-eligible families list closer schools. 


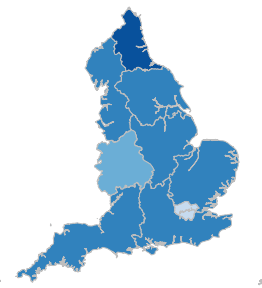

All

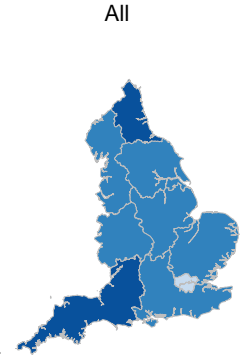

Low KS2

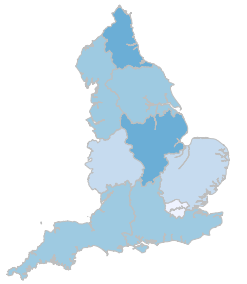

BLACK

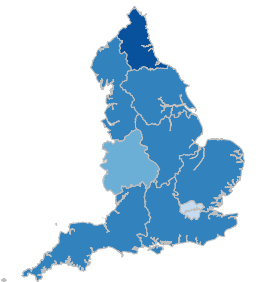

Mid KS2

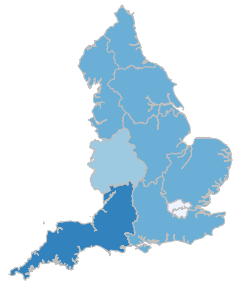

OTHER

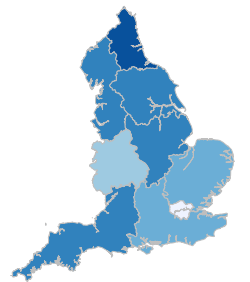

High KS2

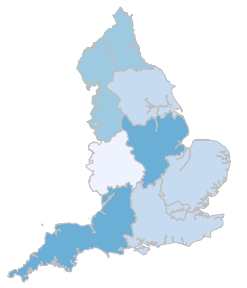

SOUTHASIAN

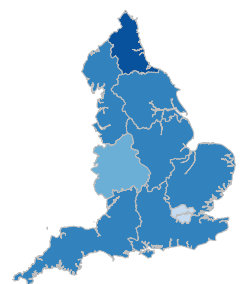

Not PP

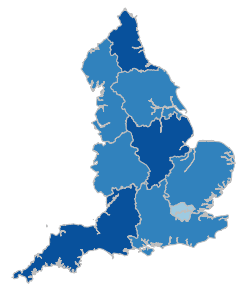

WHITE

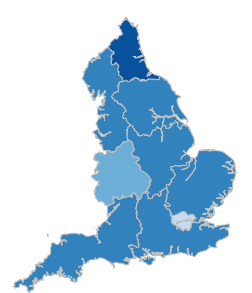

Pupil Prem.

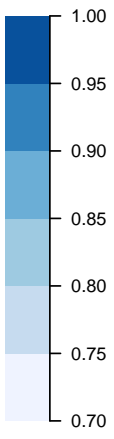

Figure 13: Proportion admitted to listed schools by region and demographics. There is considerable regional variation, and relatively stable differences by demographic in each region.
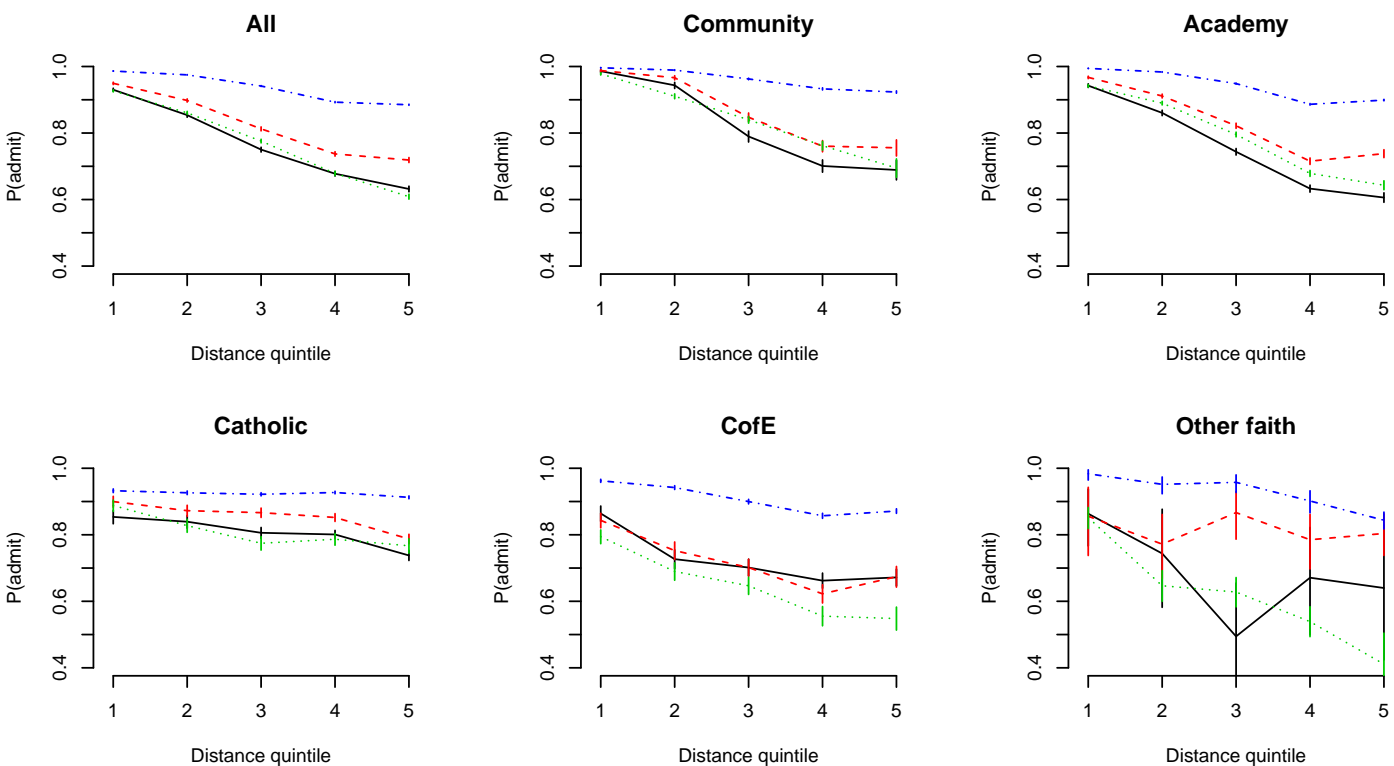

$\rightarrow$ BLACK

- - OTHER ‥ SOUTHASIAN $\bullet-$ WHITE

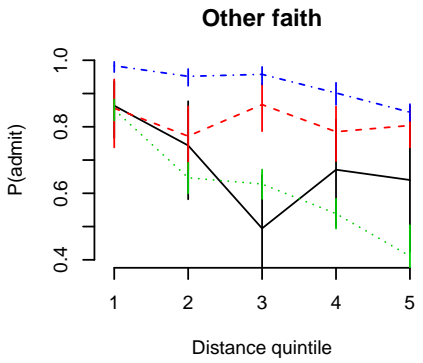

Figure 14: Proportion admitted to listed schools by distance quintiles and demographics. Quintile thresholds are the same for all demographics. The striking pattern is that, at all distances, white children are more likely to be admitted than other ethnic groups, even in community schools, and for this group the proportion admitted remains high as distance increases. This suggests an explanation that takes into account differences in strategic school selection. 


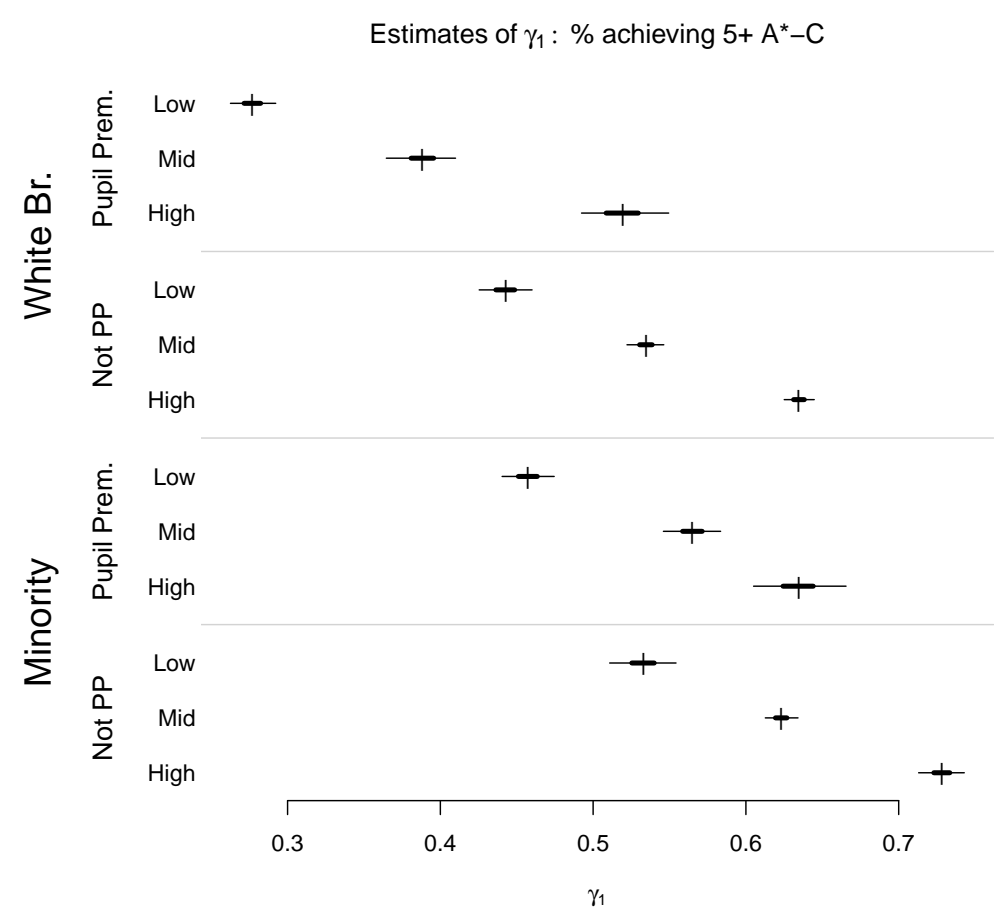

Figure 15: Estimates of $\gamma_{1}$ : preference for $\%$ achieving at least $5 A^{*}-C$ at GCSE.

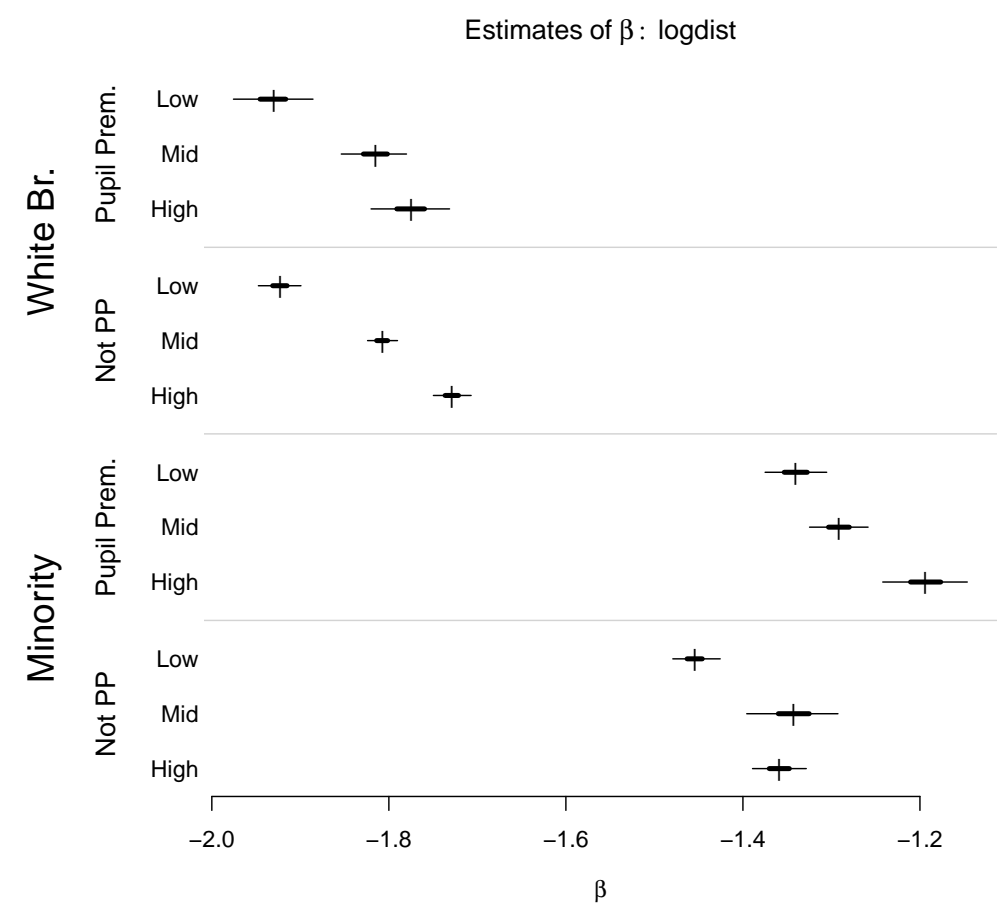

Figure 16: Estimates of $\beta$ : preference for $\log ($ distance). 


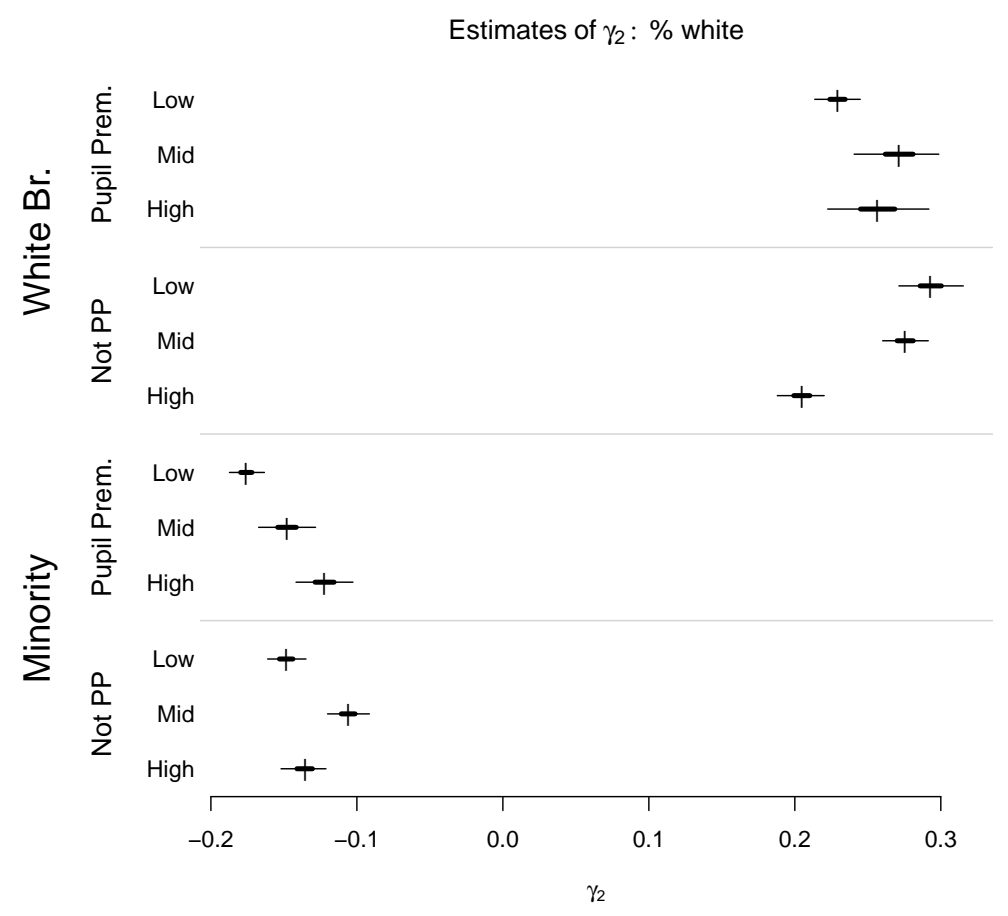

Figure 17: Estimates of $\gamma_{2}$ : preference for $\%$ white at school.

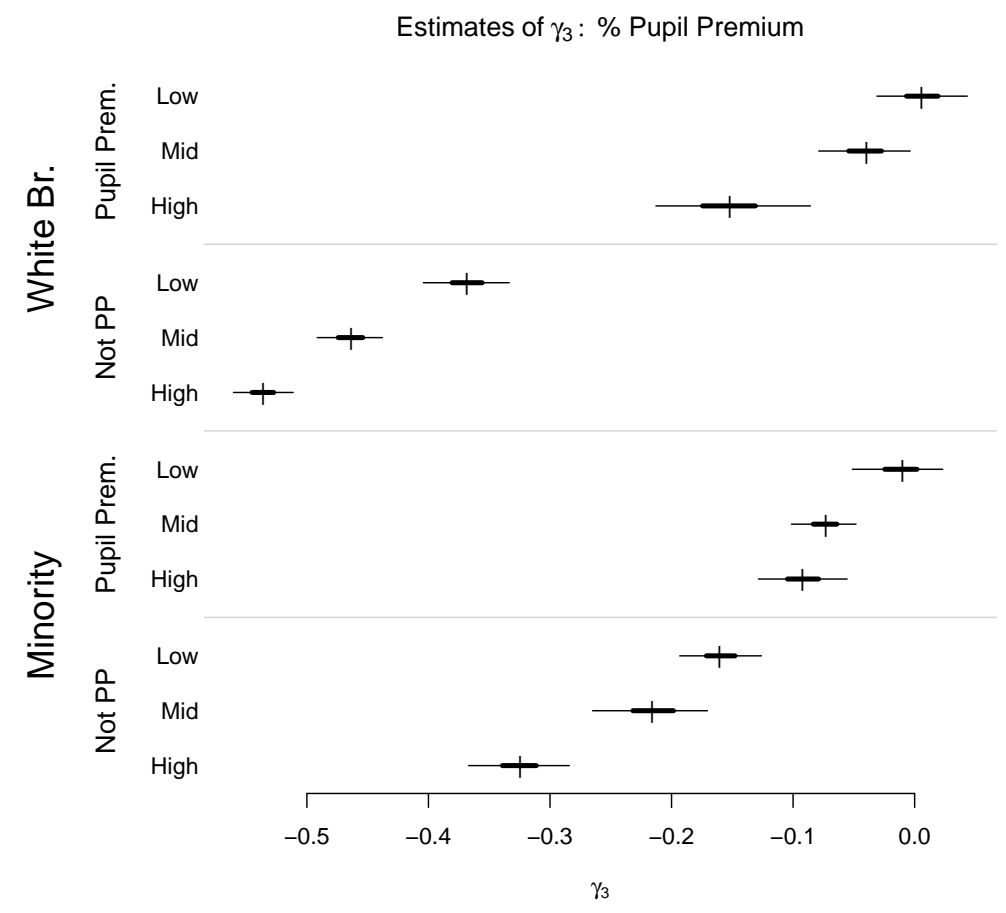

Figure 18: Estimates of $\gamma_{3}$ : preference for \% Pupil Premium at school. 


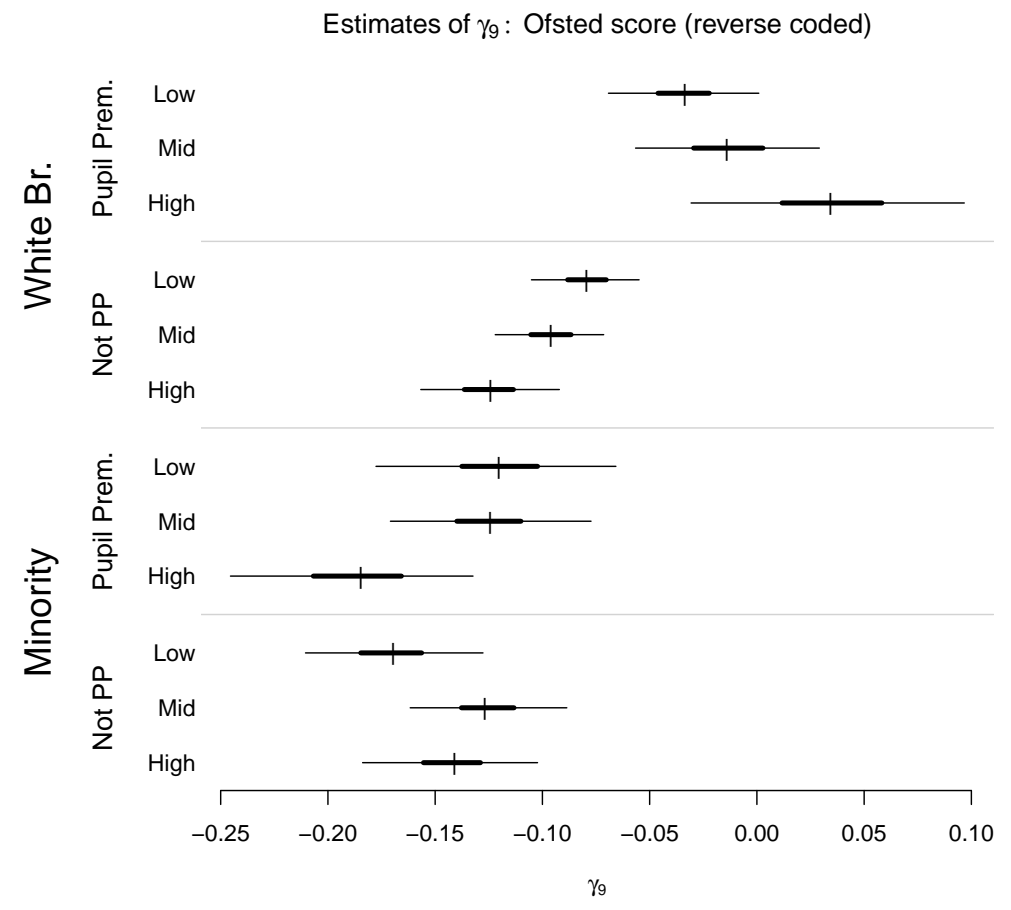

Figure 19: Estimates of $\gamma_{9}$ : preference for good school inspection (Ofsted) scores. Large negative effects indicate strong preferences for Ofsted achievement, as scores are reverse coded and treated as continuous: 1 $=$ Outstanding; $2=$ Good $; 3=$ \{requires improvement, special measures $\}$. 

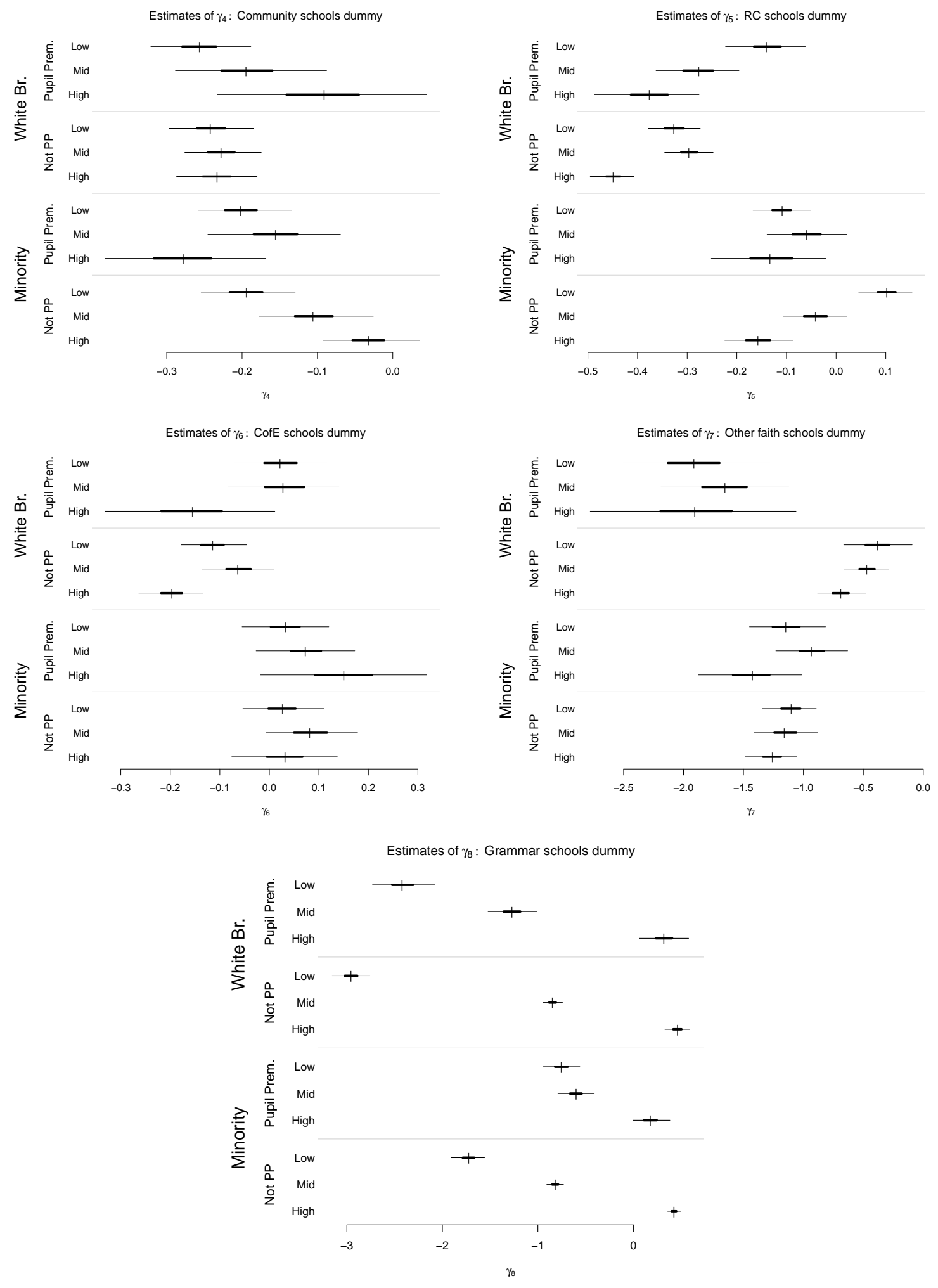

Figure 20: Estimates of $\gamma_{4}-\gamma_{8}$ : preferences for school types. 